\title{
Energy saving and efficiency
}

\author{
EDDY JANSSEN \\ University of Antwerp, Faculty of Applied Engineering - Antwerp, Belgium
}

\begin{abstract}
Summary. - Many products and package systems offered by manufacturers have been optimized under pressure from Europe's eco-design regulations (e.g., Energy Related Products). This also gives the customer access to reliable product information at the time of purchase, which continuously encourages manufacturers to improve the energy efficiency of their products in order to remain competitive. Typical of this merchandise is mass production. The focus in this article is on the design of energy efficient thermal systems, where each installation is custom made and consists of an assembly of components. Two groups with a large share in energy consumption need a different approach: industrial processes and building facilities. Pinch Point Analysis provides a systematic method to save energy in industrial plants through optimal implementation of heat recovery, cogeneration and heat pump applications. On the other hand, the Hysopt simulation software offers a powerful and accessible tool for optimizing the heat generation and distribution network that allows energy savings in buildings. After an introduction, both Pinch Point Analysis and Hysopt are explained, with designers in particular being the target group.
\end{abstract}

\section{1. - Introduction}

Of all anthropogenic greenhouse gases, $\mathrm{CO}_{2}$ emissions have by far the greatest impact on the climate. The emissions originate mainly from fossil fuels, which have been responsible for most of our energy supply for over a hundred years. According to the reports of the Intergovernmental Panel on Climate Change (IPCC), it is urgent to take drastic measures to avoid dangerous tipping points and irreversible climate changes. $\mathrm{CO}_{2}$ emissions need to be reduced by $50 \%$ within 10 years and this effort must be repeated for 
several consecutive decades. It is clear that this will be extremely difficult, but mankind faces this overwhelming responsibility to future generations.

In order to reduce our dependence on fossil energy, a lot of efforts have already been made in the renewable and nuclear energy sector, but progress seems too slow to resolve the climate problem. A significant part of the solution is expected from an unprecedented technological development in energy generation, which frequently offers additional benefits such as more employment and better air quality. Unfortunately that effort will not be sufficient.

It is clear that part of the solution will consist of an improvement in efficiency $\left({ }^{1}\right)$, not only in electrical applications and mobility, but also in heating and cooling applications. The latter is the subject of this paper. It may be useful to designers of technical installation.

1`1. Trias energetica. - Note that the industry applies a short payback period in their decisions for investments in energy saving. In combination with the current energy prices which are very low, it is clear that there would be an enormous savings potential if investors would accept a longer payback period.

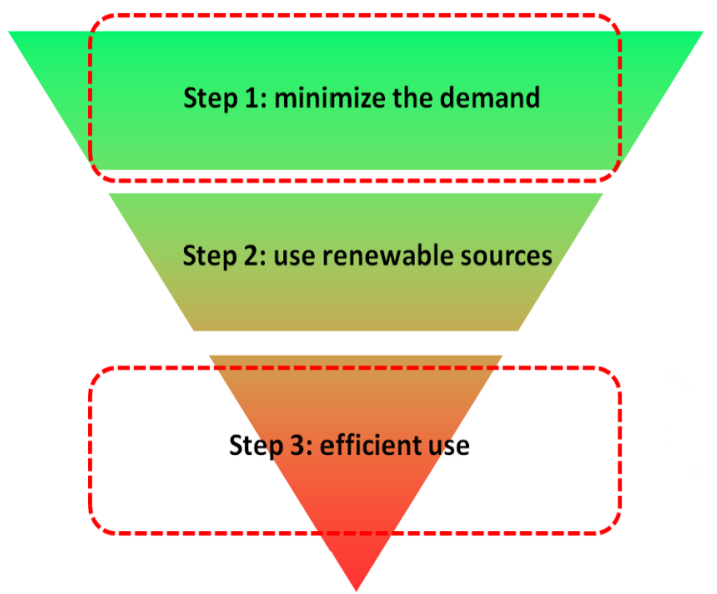

Fig. 1. - Trias Energetica and efficiency [8].

The Trias Energetica as shown in fig. 1 is a model developed by Delft University of Technology as a guideline in the pursuit of economically interesting $\mathrm{CO}_{2}$ reduction in the construction sector. It is of course also applicable in other sectors.

The Trias Energetica describes 3 consecutive steps that must be performed, in which especially steps 1 and 3 are linked to efficiency: minimize the energy demand and efficient use of energy.

( ${ }^{1}$ Knowing that $1 \mathrm{kWh}$ that is not consumed equals $1 \mathrm{kWh}$ that does not have to be produced, saving energy offers opportunities that can have a rapid effect. 
1'2. Primary and secondary energy. - Although electricity is increasingly being collected from the wind and the sun, heat is still the most important primary energy source for the production of work and electricity. Heat can of course also be used directly for thermal applications, e.g. heating of buildings and industrial processes.

Heat (or thermal energy) and work (or mechanical energy) differ in application and price. It is wrong to state that a heat pump with a $\operatorname{COP}\left({ }^{2}\right)$ of 4 simply needs 4 times less energy than a gas boiler with an efficiency of $100 \%$. For a correct comparison, one must take into account all the energy required for the end result. That is why there are the concepts of primary and secondary energy. Primary energy is energy from raw materials in their natural state, before technical conversion, e.g. crude coal, natural gas, uranium ore, solar radiation etc. Secondary energy is made from primary energy but is easier to handle for end users, e.g. electricity, compressed air, steam, hot water, cooling water, ice water etc.

An average efficiency of $40 \%$ for electricity generation means that $2.5 \mathrm{kWh}$ of primary energy is needed per $\mathrm{kWh}$ of electricity. The remaining energy is lost or converted to heat during the production of electricity, transformation to high voltage, long-distance transport using high-voltage lines, transformation to low voltage and local distribution via the low-voltage network.

Fuel-based heat generation also requires energy for extraction, processing and transport. The ratio of the required primary energy and secondary energy at the consumer level is on average 1.08 for fuel oil, 1.07 for natural gas and coal, and 1.01 for firewood. However, these values are highly dependent on the source, more precisely its quality, location and availability.

13. Basics on energy conversion and thermodynamic cycles. - The first law of thermodynamics, well known as the law of energy conservation, only dictates the amount of energy, while the second law takes into account that energy processes have a preferred direction of progress. So heat always flows from a higher to a lower temperature, and no thermodynamic cycle is possible in which heat is fully converted into work. A thermodynamic cycle consists of a sequence of processes that involve transfer of heat and work into and out of the system, while varying state variables within the system. After a cycle, the system returns to its initial state. By repeatedly executing this process, one obtains a motor or a heat pump, depending on the direction of the energy flow and consequently the sense of rotation in a state diagram: clockwise or counter-clockwise.

A positive thermodynamic cycle is the conversion of thermal energy into useful work, whereby transferring the remaining heat to a cold sink. Carnot taught us that the efficiency of such a heat engine increases as the temperature of the hot source is higher and the temperature of the cold source is lower. The limits for these temperatures are imposed by the availability of both sources, the material properties and the process

$\left({ }^{2}\right)$ COP: The efficiency of a heat pump or a refrigerator is referred to as the "coefficient of performance", the ratio of useful heating or cooling provided to work required. The distinction with efficiency is that it usually exceeds $100 \%$. 
design. Conversely, this cycle can be reversed to a negative thermodynamic cycle, where heat flows from a lower to a higher temperature, in contrast to the natural heat flow. The applications are the production of cold (chiller) or heat (heat pump), usually based on compressing and the use of work. In a similar way, Carnot taught us that the efficiency of such a negative thermodynamic cycle increases as the temperature of the hot source and the cold source are closer to each other.

1*4. Technologies for energy conversion. - There are many technologies to transform energy, and in each specific application it is interesting to investigate which one is optimal. Let's examine a simple case, assuming a modern kitchen. The question is: what is the best way to defrost $10 \mathrm{~kg}$ of frozen soup?

To do this, approximately $1 \mathrm{kWh}$ of heat must be added. This corresponds to heat the same amount of water from $0{ }^{\circ} \mathrm{C}$ to $80^{\circ} \mathrm{C}$. To realize this, we can place the soup in the microwave, on the gas cooker, on the sideboard, in the open air or in a refrigerator. Each option has an extremely different primary energy consumption. In the following calculations we assume an efficiency of $50 \%$ for electricity production and a COP of 3 for cooling.

1) The microwave uses an expensive form of energy that is generated in a power plant with an efficiency of 35 to $55 \%$, so that every $\mathrm{kWh}$ of heat to be supplied costs an average of $2.5 \mathrm{kWh}$ of primary energy.

2) In the case a gas cooker is used, the inevitable loss of heat ends up in the kitchen, so that during winter the efficiency can be said to be $100 \%$. Placing on the sideboard is energetically comparable because this process takes heat away from the kitchen, so that in winter conditions the boiler, which has an efficiency near to $100 \%$, has to produce an amount of heat that equals the chill. Therefore, each $\mathrm{kWh}$ of heat to be supplied costs $1 \mathrm{kWh}$ of primary energy. This seems to be optimal, but it is not.

3) By placing the soup outside, the defrosting process does not cost any primary energy because the environment supplies all necessary energy. This is called "free heating", just as there is "free cooling". Both can only be used when the temperature conditions are appropriate, because heat is only transferred from high to low temperature. For example, the soup can only be defrosted outside when it is not freezing, and the colder it is outside, the longer the defrosting process takes. Again this seems to be optimal, but it is not.

4) By placing the frozen soup in the refrigerator which has a temperature of +2 to $+4{ }^{\circ} \mathrm{C}$, the refrigerator consumes less electricity because the chill is recovered. Every $\mathrm{kWh}$ of chill saves $0.33 \mathrm{kWh}$ of electricity and $0.67 \mathrm{kWh}$ of primary energy.

The refrigerator is not only the most energy-friendly way of defrosting. For food safety reasons, it is recommended that the temperature is kept below $4^{\circ} \mathrm{C}$, so that the refrigerator is also the best in that respect. Fast heating in the microwave or stove is a safe alternative, but is energetically the less interesting way. It is clear that an uncontrolled and long open-air defrost time is not recommended, although common practice.

Most of the people are acting out of habit, but the example shows that this is often far from optimal. The difference in primary energy is remarkable, grading from a huge 
consumption to a considerable gain. In this example we are lucky because the most efficient way is also the best in preventing the growth of pathogenic germs. To practice this, one must know a day in advance what we will eat. In other words energy can be saved by considering and planning. This example in the domestic sphere demonstrates that also in industrial processes, a confrontation between different alternatives can result in large energy savings.

\section{2. - Energy circle}

To facilitate a selection between the many conversion technologies in order to minimize the primary energy consumption, these are visualized in a perfectly symmetrical diagram of fig. 2, called the energy circle.

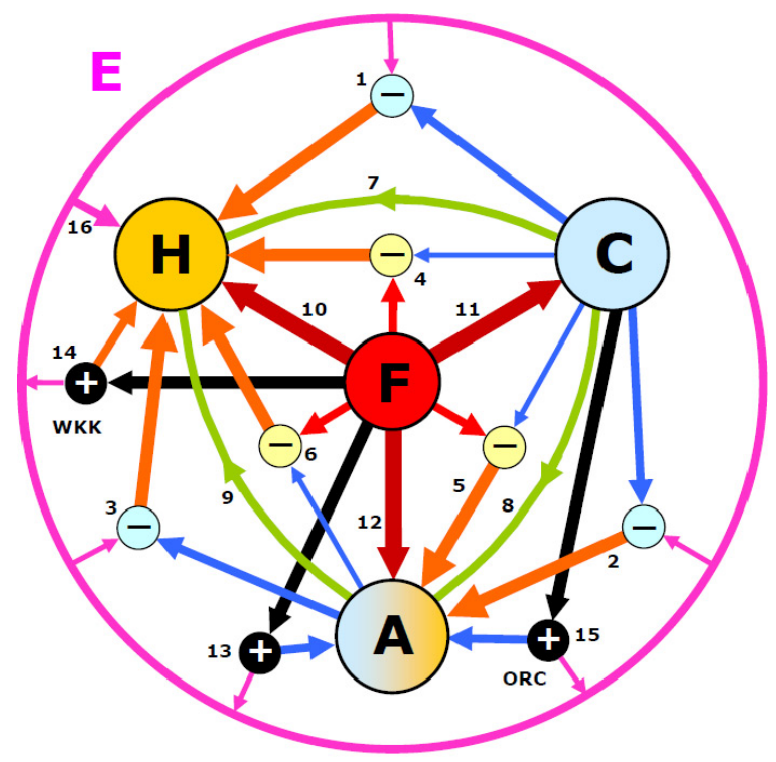

Fig. 2. - Energy circle [7].

The arrows not only show the direction of the energy flow, but also qualify the size (width of the arrow) and the energy quality (from red = warm, over orange, to blue $=$ cold). The aim is to gain insight on how to save energy and thereby reduce the $\mathrm{CO}_{2}$ emissions and the energy cost. The energy cycle is built around 5 elements as suggested in fig. 3: $\mathrm{A}=$ Ambient (air, water, soil); $\mathrm{C} \& \mathrm{H}=$ Cooling \& Heating load (buildings, industry); $\mathrm{E}=$ Electricity (electricity, electricity network); F = Fuel, fossil or renewable (to be regarded as the primary energy).

Between these 5 elements there are numerous technologies to meet the needs for cooling, heating and the production of work. Some are purely based on heat transfer, such as condensing boilers that most of the time use fossil energy, or heat exchangers 


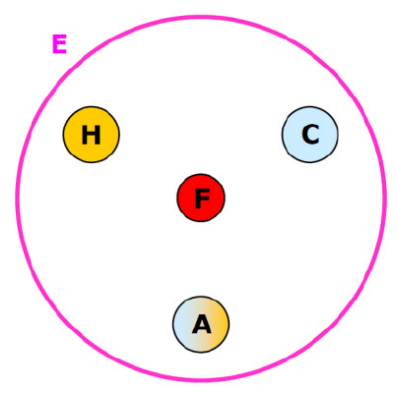

Fig. 3. - The 5 elements.

like dry coolers and cooling towers that can be used for heat recovery and free cooling. Other technologies consist of a negative thermodynamic cycle. Most of them are based on mechanical compression, and use work or electricity. There are also machines based on thermal compression by sorption, using heat. The aim is to transfer heat from a lower to a higher temperature, with cooling (chillers) and heating (heat pumps) as applications. Finally, the goal of a positive thermodynamic cycle is to generate work or electricity starting from thermal energy. In addition to the common power plants that only generate electricity and dissipate outgoing heat to the environment, cogeneration or combined heat and power is an alternative with an improved efficiency, beside an organic Rankine cycle that can generate electricity from residual heat at a relatively low temperature.

$2 \cdot 1$. Pure heat exchange starting from primary energy. - Technologies that are purely based on heat transfer form fossil or renewable fuels do not require electricity, as presented in fig. 4.

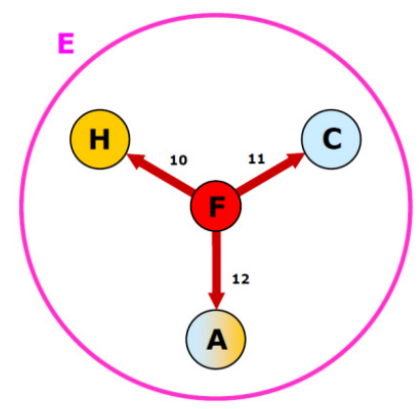

Fig. 4. - Heat exchange starting from primary energy.

The most common are boilers (see no. 10 in fig. 4). Their emissions and efficiency have greatly improved in recent decades, so it can be said that they are fully developed. Many obsolete boilers with a suboptimal performance are still in use, and a huge improvement is possible by renewing them. A point of attention when selecting boilers is the ratio between the maximum and minimum power, as this determines the dynamic behavior 
under partial load and can improve overall efficiency. Another important property is the water content of a boiler and the resulting minimum required flow rate that determines the possible hydronic configurations. To gain insight into this, the software "Hysopt" is clarified later in the text.

Two situations to be avoided complete the picture. First, heating something which has to be cooled (see no. 11 in fig. 4) is obviously energy destruction. Indeed, energy is consumed by the heat production process itself, and due to the incorrect application, the cooling load increases. This situation in which heating and cooling take place simultaneously is always the result of errors, and unfortunately happens too often. It can be the result of an incorrect control algorithm or bad commissioning.

Secondly, heat generated by combustion is very often discharged directly into the environment, which can be called energy loss (see no. 12 in fig. 4). In industry it is typically applied to reduce emissions, for example to convert methane into water vapour and $\mathrm{CO}_{2}$ in order to reduce global warming. It can also be applied for safety reasons, for example flaring. It can also occur by accident, e.g. in case of fire.

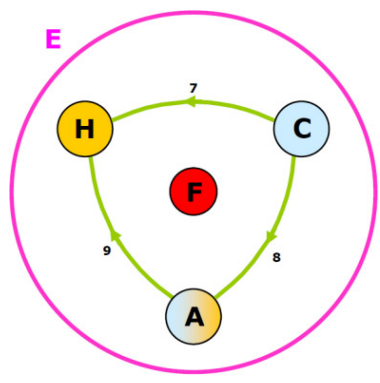

Fig. 5. - Heat recovery, free cooling and free heating.

2:2. Free heating and cooling. - Figure 5 demonstrates three applications of heat exchangers. They comply with the law of energy conservation and need a temperature difference for heat transfer. If cooling is required at a temperature higher than the temperature of a heat demand elsewhere, heat recovery can be applied (see no. 7 in fig. 5). Apart from auxiliary energy for pumps or fans, no electricity or fuel is required, and two needs are simultaneously met, which is optimally in that regard. Conversely, if there is to be cooled, while there is no simultaneous heat application below that temperature, heat recovery is impossible unless additional investments are made in heat storage or heat pumps.

Free cooling (see no. 8 in fig. 5) is the best alternative for dissipating the heat that is released during cooling, because no extra energy is needed. It can be applied on condition that the ambient temperature is lower than the temperature of the object to be cooled. Evaporation of water in cooling towers or adiabatic dry coolers lowers the target temperature to the wet bulb temperature, which improves the applicability of free cooling and offers opportunities for energy saving. 
Heat can also be collected from the environment, e.g. thermal solar energy or deep geothermal energy. The applicability of this so-called free heat (see no. 9 in fig. 5) depends strongly on the location.

$2 \cdot 3$. Positive thermodynamic cycle for the production of electricity. - A positive thermodynamic cycle consists of the conversion of thermal energy or heat into mechanical energy or work, whereby part of the energy is released as heat at a lower temperature. Note that work can easily be converted into electricity. Figure 6 shows three applications. In no. 13 in fig. 6 the released heat is discharged into a river or the atmospheric air, using heat exchangers such as cooling towers that are well known form nuclear power plants. This is called "separate" production of heat and electricity since boilers are used to meet the heat load for industry and buildings.

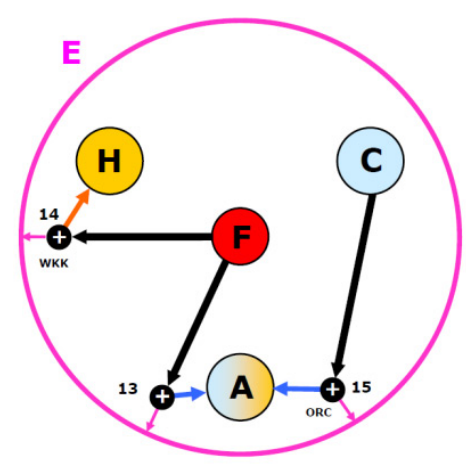

Fig. 6. - Positive thermodynamic cycles.

Note that part of the heat, generated by an engine of a car, can be recovered to heat the passenger's compartment. This is one example of the so-called cogeneration $\left({ }^{3}\right)$ (see no. 14 in fig. 6). CHP based on piston engines with internal combustion of natural gas is used for small capacities from $1 \mathrm{~kW}$ to $10 \mathrm{MW}$ electric power. The smallest machines are relatively expensive and have an unfavourable heat-to-work ratio. On the other hand gas- and steam turbines are used for applications with larger capacities. The best available technology can respond to the variable heat load by modulating between CHP for maximum overall efficiency, and the production of electricity exclusively for a higher electrical efficiency but a lower overall efficiency. Typical for CHP is the proximity of a heat user, because heat cannot be transported over very long distances. Due to the high investment, it is strongly recommended to dimension a CHP for the basic load in order to achieve a large number of operating hours per year. An appropriate hydronic configuration is essential in order not to exceed a maximum allowable return temperature.

An Organic Rankine Cycle (ORC, see no. 15 in fig. 6) can be compared with the Rankine cycle such as in steam turbine installation, but applied with an organic substance

$\left({ }^{3}\right)$ Cogeneration or combined production of heat and power $(\mathrm{CHP})$. 
instead of steam. Due to the material properties, waste heat at a lower temperature can be converted into electricity. Although the efficiency is low (5-20\%), it can be economical in cases with a large number of operating hours per year.

$2 \cdot 4$. Negative thermodynamic cycle for the production cold or heat. - A negative thermodynamic cycle consumes work to transfer heat from a cold source to a warm sink. Thereby it is acting as a cooler or a heat pump, depending on the needs.

$2 \cdot 4.1$. Negative thermodynamic cycles based on compression. A negative thermodynamic cycle may be based on compression, usually driven by an electric motor. The three different applications are presented in fig. 7. For example it can be applied for cooling (see no. 2 in fig. 7) in which the released heat is dissipated, e.g. a split unit in which the outdoor unit discharges heat into the outside air during the summer. The same principle can be applied for heating (see no. 3 in fig. 7), whereby free heat is extracted from outside. Because work of electrical origin is converted into heat, it is only less expensive for the consumer when the ratio "electricity price to fuel price" is lower than the COP. The heat pump may score better on the $\mathrm{CO}_{2}$ benchmark, depending on how the electricity is produced, e.g. nuclear power stations or renewable energy, but not coal-fired power stations.

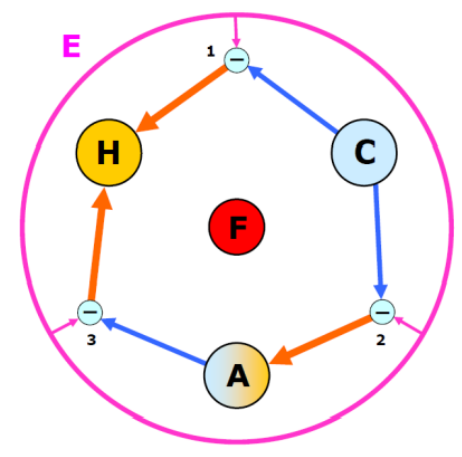

Fig. 7. - Negative thermodynamic cycles - compression based.

Last but not least, a negative thermodynamic cycle can be used for both heating and cooling (see no. 1 in fig. 7). The most interesting applications are those with a small temperature step for a high COP. A common refrigerator in a kitchen returns its released heat back into the kitchen, so this is an application of heat recovery from cooling. Note that this also takes place during summer when people prefer not to have any heat source. Another example is the cooling racks of supermarkets. During the summer, the released heat can be dissipated outside so that the racks contribute to the cooling. During the winter, the released heat can be dissipated indoors to contribute to the heating. Note that the released heat is removed too often while a boiler is used to generate heat again.

$\mathbf{2}$ 4.2. Negative thermodynamic cycle based on sorption. A negative thermodynamic cycle may also be based on sorption, to be regarded as a compression that is driven by 
thermal energy. The same applications of compression processes described above exist, as presented in fig. 8. The most common application is absorption cooling (see no. 5 in fig. 8). The poor performance is not a major disadvantage, since the heat that is consumed usually comes from an industrial process with excess heat that is otherwise rejected. Another application is the absorption heat pump driven by natural gas (see no. 6 in fig. 8). It extracts heat from a dry cooler or a borehole storage.

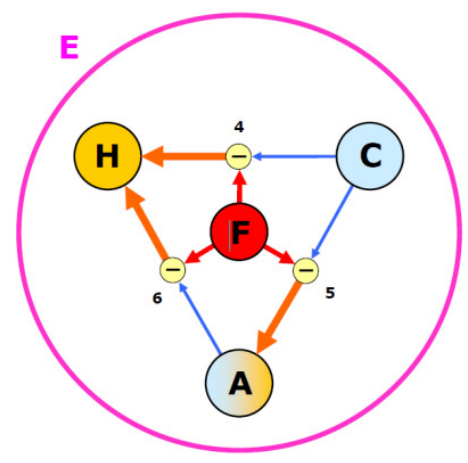

Fig. 8. - Negative thermodynamic cycles — sorption based.

The combination of a heat pump (compression or absorption) and storage offers the possibility of cooling during summer with the chill stored during winter. The energy flows are very similar to a gas boiler because they use the same energy source and provide heat in the same temperature range. The difference is the higher investment and the fuel savings due to an efficiency of up to $170 \%$. In this definition, the electricity consumption of the liquid pump is not taken into account. The efficiency (COP around $400 \%$ ) is significantly lower than in the case of compression heat pumps. As a result, absorption heat pumps require a considerably smaller cold storage, but at the same time they have a smaller cooling capacity.

2.5. Electric heating. - Electricity can also be converted into heat, as symbolized in fig. 9. The applications for heating buildings are greatly reduced due to the electricity costs (electricity is much more expensive than fuel), knowing that there is a huge energy loss in the generation of electricity. However, two important applications remain.

Due to extensive insulation and wind proofing of buildings, energy consumption may decline to such an extent that the low investment and good controllability of electric heating can be decisive. This brings electric heating back into the scope, with technologies based on direct heating or accumulation, radiation or convection etc.

Another application is heating at a very high temperature such as electric welding and other industrial processes. Various technologies can be applied, depending on the application: resistors, induction, plasma arc, high-frequency waves, infrared radiation, .... The heat supply is easy to control, and some techniques allow locally heating, which benefits energy efficiency and often also the product quality. 


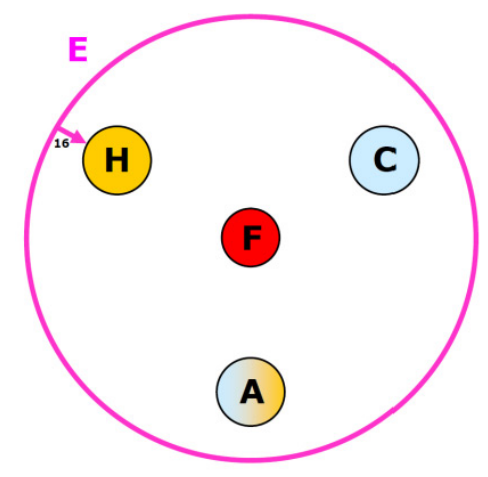

Fig. 9. - Electric heating.

2*6. Hybrid systems. - All processes described above can be combined into hybrid systems in order to improve energy efficiency by responding to changing conditions. These systems are complex to regulate and to design. The Hysopt software is a powerful tool to meet this load, and will be discussed later in this text. The energy circle proposed here is useful for training, by mapping the different energy flows which makes it easier to calculate the primary energy (the arrow departing from F).

- Example 1: Trigeneration or combined cooling, heat and power (CCHP) as shown schematically in fig. 10, refers to the simultaneous generation of electricity, heating and cooling, powered by an engine or a solar thermal collector. Applications for residential buildings can be based on a compression heat pump (see no. 3 in fig. 10) powered by a gas engine (see no. 14 in fig. 10). During winter, both the engine (CHP) and the heat pump must be used for the heat supply. During the summer, often only the heat load for domestic hot water remains and that can be supplied by the engine heat, used as CHP. In that case, the heat pump can be used as an engine-driven cooling machine (see no. 2 in fig. 10).

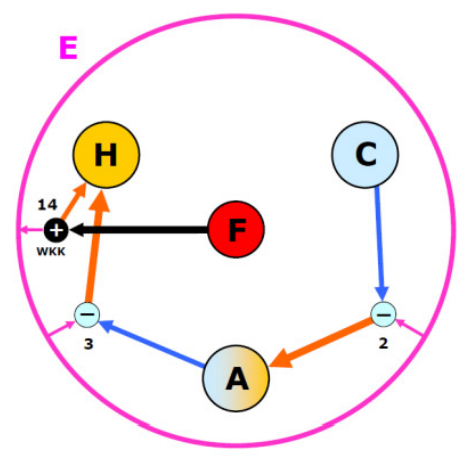

Fig. 10. - Hybrid system: CCHP. 


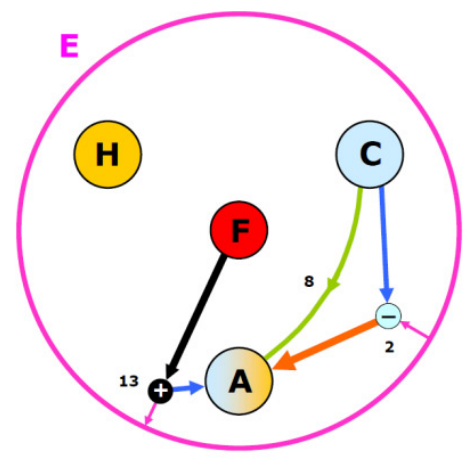

Fig. 11. - Hybrid system: free and active cooling.

- Example 2: In fig. 11 the focus is on cooling. The controller's choice between free cooling (see no. 8 in fig. 11), active cooling (see no. 2 in fig. 11) or a combination depends on the temperature conditions. According to the second law of thermodynamics, free cooling can only be applied if the object to be cooled has a higher temperature than the environment. Sometimes the ambient temperature is lower so that free cooling is possible, but the temperature difference is too low to transfer the required power. In that case, free cooling (pre-cooling without energy consumption) can be combined with active cooling, e.g. compression cooling powered by an electric motor. In fig. 11, the required electricity is generated by separate production (see no. ' 3 in fig. 11), but CHP (see no. 14 in fig. 10) is an alternative. The amount of primary energy $(\mathrm{F})$ can be reduced by applying free cooling as much as possible.

\section{3. - European energy labels}

$3 \cdot 1$. Electric motors. - Electric motors are the most important type of electric load in industries. In this application, it is easy to save energy by opting for a higher efficiency, which of course has an impact on the investment. The economic feasibility of the motor selection depends on many factors, but the purchase price is not the most important one. Even at 1000 operating hours per year and a lifetime of 15 years, the energy cost of a motor is less than $1 \%$ of the purchase cost, both for small and large motors. In this case, a higher initial purchase cost of a more efficient motor will result in high savings within a short payback period. The greater the number of running hours per year, the more economical it is to opt for high efficiency. An example of continuous operation is urban drinking water supply (see fig. 12). On the other hand, energy efficiency is less important for motors that only run sporadically.

In fig. 13 it is remarkable that the efficiency steps for large engines are relatively small, due to the technical/economic optimum explained in the calculation of fig. 14 . 


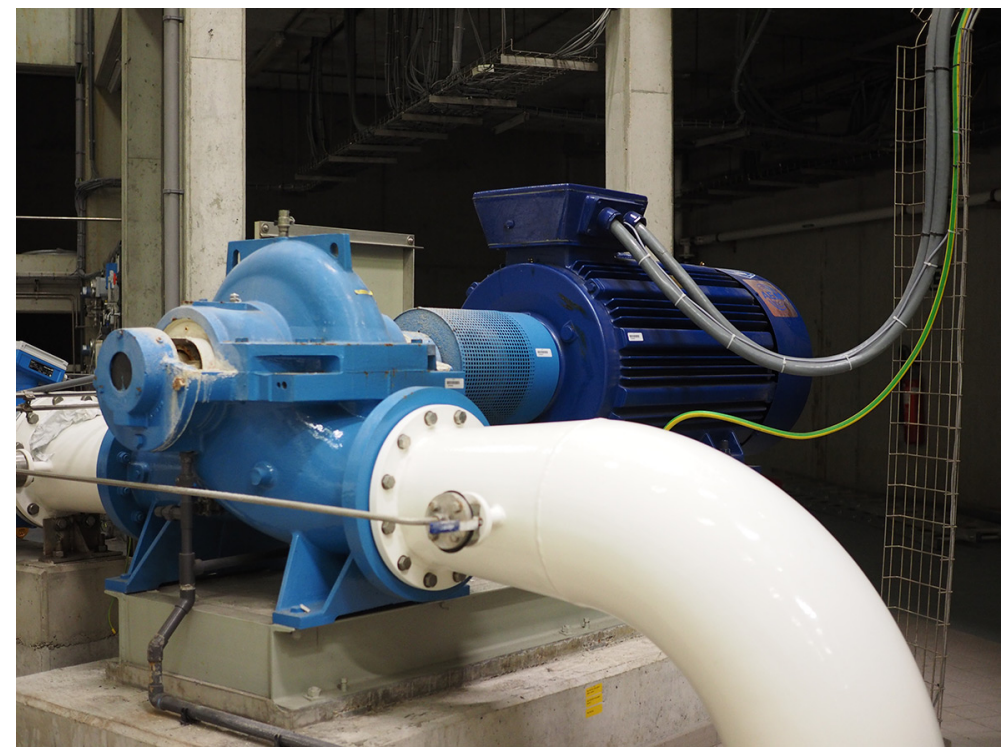

Fig. 12. - Typical example of continuous operation: pump for urban drinking water supply.

\section{IE efficiency classes for 4 pole motors at $50 \mathrm{~Hz}$}

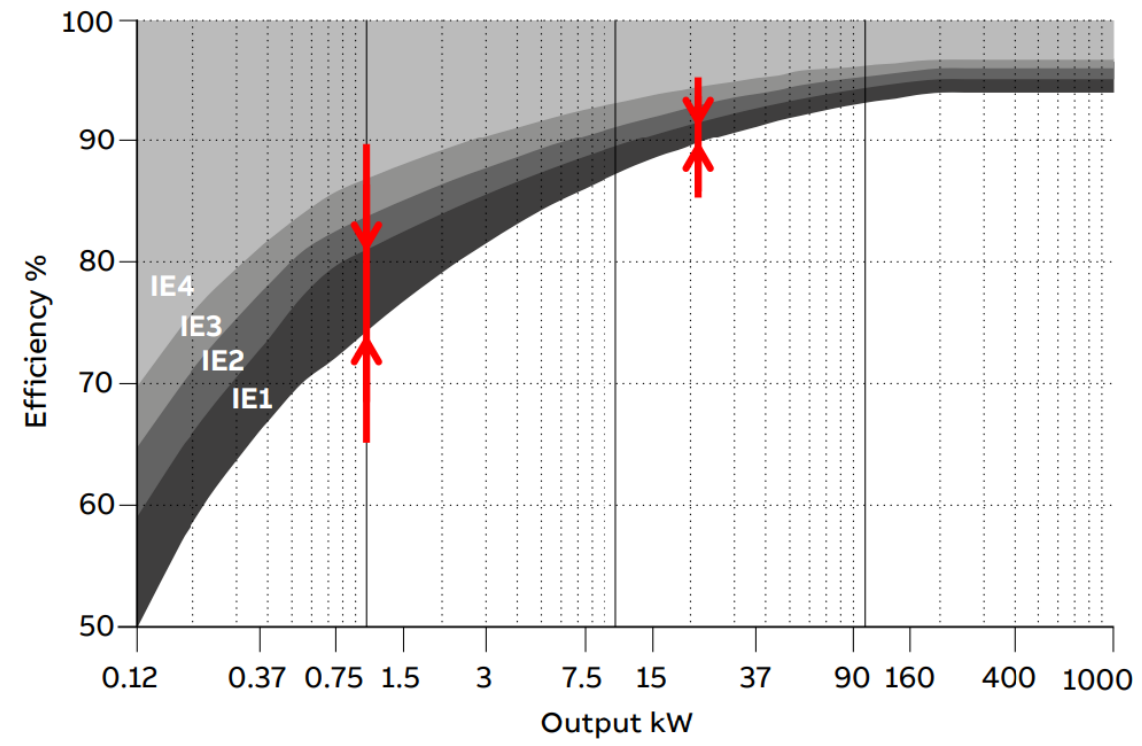

Fig. 13. - IE efficiency classes for electric motors. 


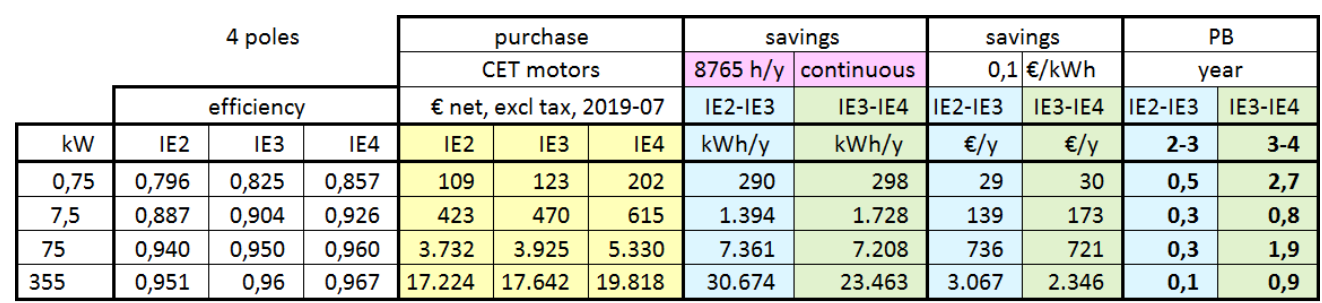

\begin{tabular}{|c|c|c|c|c|c|c|c|c|c|c|c|c|}
\hline & \multirow{2}{*}{\multicolumn{3}{|c|}{4 poles }} & \multirow{2}{*}{\multicolumn{3}{|c|}{$\begin{array}{l}\text { purchase } \\
\text { CET motors }\end{array}$}} & \multicolumn{2}{|c|}{ savings } & \multicolumn{2}{|c|}{ savings } & \multirow{2}{*}{\multicolumn{2}{|c|}{$\begin{array}{l}\text { PB } \\
\text { year }\end{array}$}} \\
\hline & & & & & & & \multirow{2}{*}{$\begin{array}{c}876,5 \mathrm{~h} / \mathrm{y} \\
\text { IE2-IE3 }\end{array}$} & \multirow{2}{*}{$\begin{array}{l}10 \% \\
\text { IE3-IE4 } \\
\end{array}$} & \multicolumn{2}{|c|}{\begin{tabular}{l|l}
0,1 & $€ / \mathrm{kWh}$ \\
\end{tabular}} & & \\
\hline & & fficienc & & $€$ net, & excl tax, & 019-07 & & & IE2-IE3 & IE3-IE4 & IE2-IE3 & IE3-IE4 \\
\hline $\mathrm{kW}$ & IE2 & IE3 & IE4 & IE2 & IE3 & IE4 & $\mathrm{kWh} / \mathrm{y}$ & $\mathrm{kWh} / \mathrm{y}$ & $€ / y$ & $€ / y$ & $2-3$ & 3-4 \\
\hline 0,75 & 0,796 & 0,825 & 0,857 & 109 & 123 & 202 & 29 & 30 & 3 & 3 & 5,1 & 26,5 \\
\hline 7,5 & 0,887 & 0,904 & 0,926 & 423 & 470 & 615 & 139 & 173 & 14 & 17 & 3,4 & 8,3 \\
\hline 75 & 0,940 & 0,950 & 0,960 & 3.732 & 3.925 & 5.330 & 736 & 721 & 74 & 72 & 2,6 & 19,5 \\
\hline 355 & 0,951 & 0,96 & 0,967 & 17.224 & 17.642 & 19.818 & 3.067 & 2.346 & 307 & 235 & 1,4 & 9,3 \\
\hline
\end{tabular}

Fig. 14. - Payback time as a function of the efficiency class, estimation for different cases.

The efficiency requirements according to the updated standard $\operatorname{IEC}\left({ }^{4}\right)$ 60034-30-1 are included in the left columns of this spreadsheet. An indicative purchase price is given for a few different capacities with their corresponding efficiency requirements. Note that the purchase price does not increase in proportion to the engine power. Two cases were chosen to calculate the energy savings: continuous full load operation (first table) and full load operation during $10 \%$ of the time (second table). Furthermore, both the energy saving (kWh/year) and the energy cost saving (€/year) are shown for an upgrade from EI2 to IE3, and also from IE3 to IE4.

It can be concluded that IE3 is very interesting compared to IE2, with a payback time less than 4 years, and even IE4 is interesting in the case of continuous full load operation. Note that the payback time becomes shorter the longer the operating time and the higher the energy price is.

3'2. Ecodesign. - Other products beside motors are covered by the EU's directive for Energy-Related Products (ErP). It does not only apply the most products that consume energy throughout their lifecycle, such as lamps and washing machines. It also covers products that do not directly use energy, but are energy-related such as windows, etc. In that context it is important to know that much energy can be saved when buying a product, simply by making the right choice. Thanks to the ErP guideline and the labels (see an example in fig. 15), consumers are better informed and can better compare the total cost of ownership. In addition, it offers manufacturers and importers an incentive to provide products that are more energy efficient.

$\left({ }^{4}\right)$ IEC: For induction motors the efficiency classes IE1 (standard) to IE4 (super premium efficiency) have been defined in order to reduce the energy consumption and the resulting $\mathrm{CO}_{2}$ emission. 


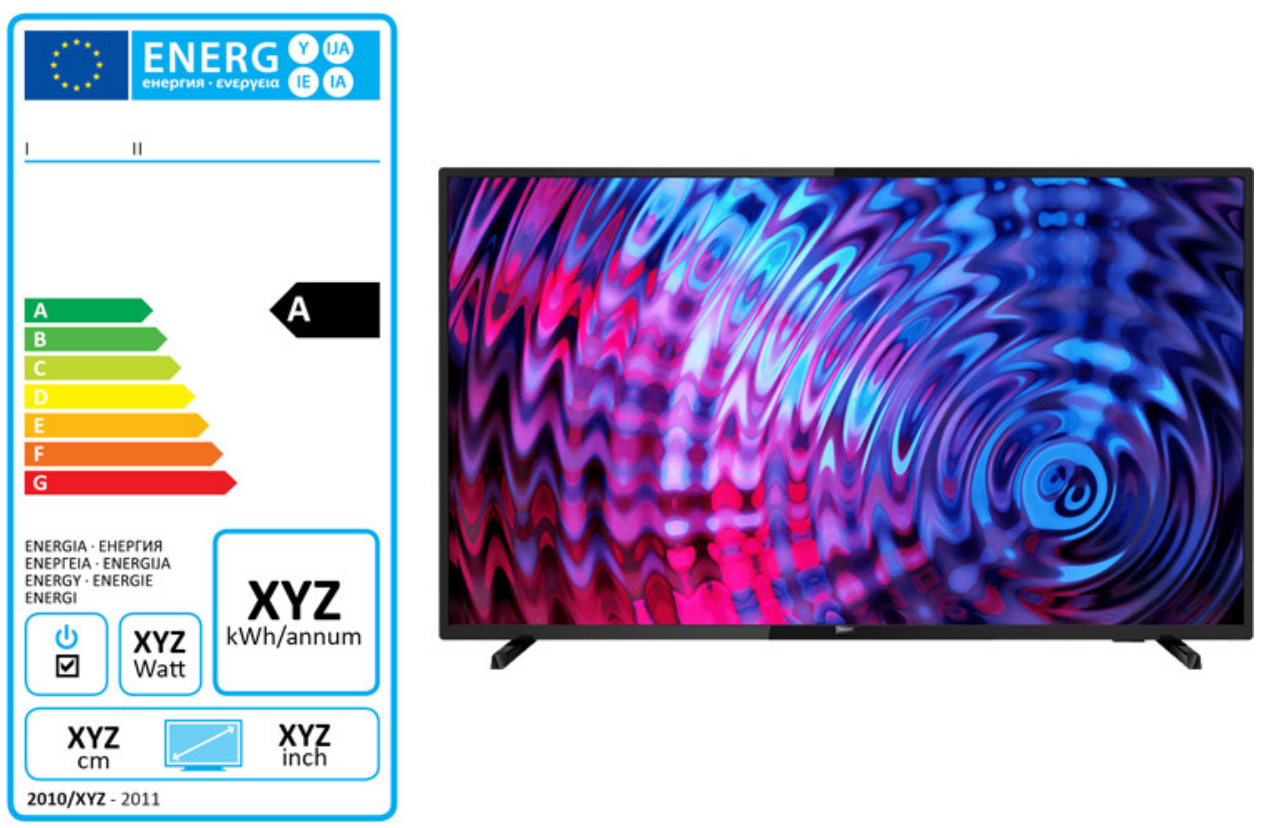

Fig. 15. - ErP-label for products.

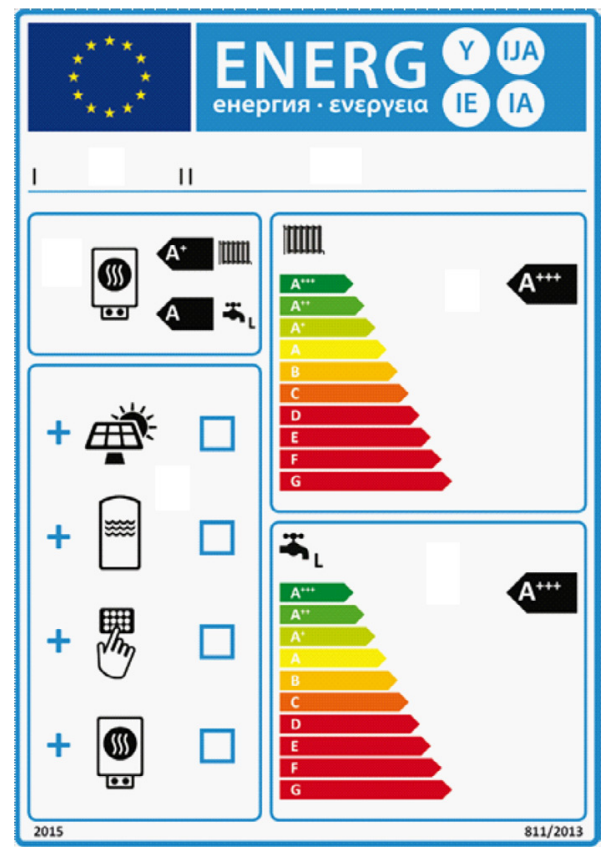

Fig. 16. - ErP-system label for ready-made systems. 
There is also the EU-directive for systems such as central heating boilers in combination with the production of domestic hot water by thermal solar energy etc. (see an example in fig. 16). These systems are optimized and ready-made offered by manufacturers.

\section{4. - Performance of customized designs}

There are labels for products and small systems, offered by manufacturers and importers. How to deal with customized, one by one designs of thermal systems? Two groups with a large share in total energy consumption need a different approach in order to minimize energy consumption:

- building facilities, especially hydronic systems for heating and indirect cooling. For this purpose, the Hysopt software has recently been developed, with steady growth in applications and users.

- industrial processes, especially total sites like the chemical industry. For this purpose the pinch technology is used on a large scale. Continuous monitoring is required due to the changing context.

4*1. Optimizing hydronic systems of buildings [1-6]. - Heating and cooling in buildings cause a large $\mathrm{CO}_{2}$ emission. These systems are usually based on hydronic heat distribution where water is pumped in a closed circuit over heat exchangers and control valves. A gap between expected and actual performance, beside other shortages, is often due to a lack of performance-based engineering tools. Notice that having access to correct components is no guarantee for a performing installation. Often the return temperature is too high, CHP and heat pump's lack running hours, condensing boilers are not condensing, flow rates are not balanced, etc. resulting in energy loss and discomfort.

Until the release of Hysopt it was impossible to calculate the saving potential of hydronic optimization, both in renovations and new constructions. However, this is very important for convincing building managers. As a result, the latter wait too long with renovations, even under economically interesting conditions, and opportunities for saving are missed.

Secondly, much attention is paid to the development of high-performance components, but when designing and assembling them into systems, things often go wrong, leading to sub-optimal systems. While mass-produced products get a very smart preparation, and industrial processes are not possible without a strong technical team, building facility and hydronic networks like central heating systems are different. Every building is unique, and it seems that the technical installation always has to be reinvented. Moreover, there is often poor commissioning, also leading to sub-optimal systems in terms of energy and comfort.

The problem is often due to the design process, in which engineers have not enough time or skills to design for performance. Systems are typically designed for full load conditions, however the behaviour and performance of the installation under partial load operation determines the overall performance. In addition, the integration of more sustain- 


\section{Equilibrium: $\quad P_{\text {out }}=P_{\text {in }}$}

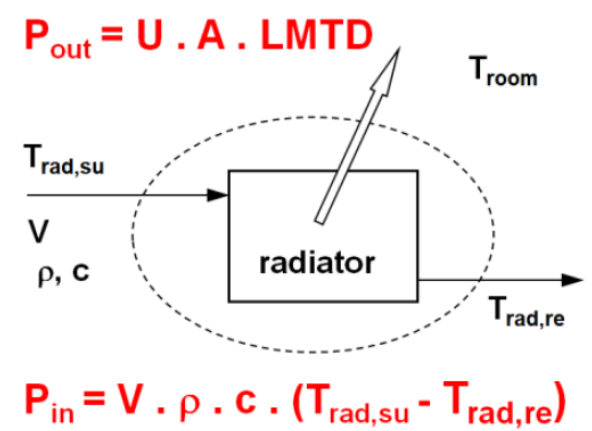

Fig. 17. - Stationary state, energy balance: $P_{\text {out }}=P_{\text {in }}$.

able heating and cooling components in hybrid systems creates new levels of complexity and the number of possible hydraulic configurations and control strategies is exploding.

Hysopt, a spin-off company from the University of Antwerp, is closing this performance gap with its powerful design and simulation software, which introduces transparency and performance into the design process of large heating and cooling systems.

$4 \bullet 1.1$. Hydronics, a brief introduction. Suppose a hydronic system like the central heating system of a school in a situation of equilibrium. In- and outgoing power of a radiator is based on the equations of a heat exchanger, as shown in fig. 17.

Apart from combinations, there are two methods for power regulation: controlling the water temperature $v s$. the water flow. Only the most obvious ways of realizing these control options are described in fig. 18. Heat exchangers like radiators have different

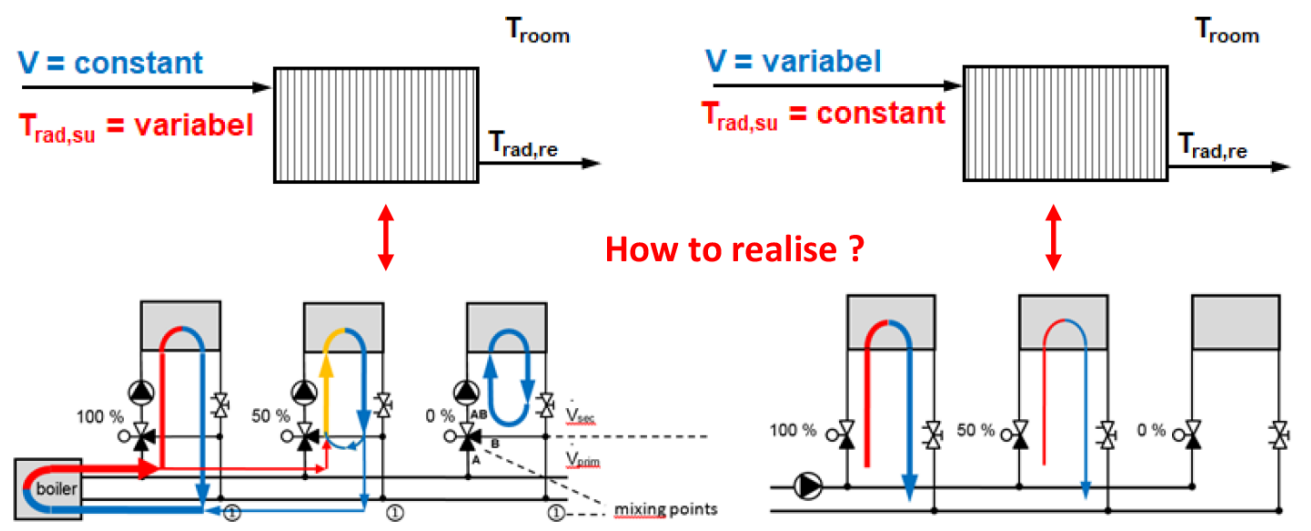

Fig. 18. - In- and outgoing energy flows in a steady state system. 

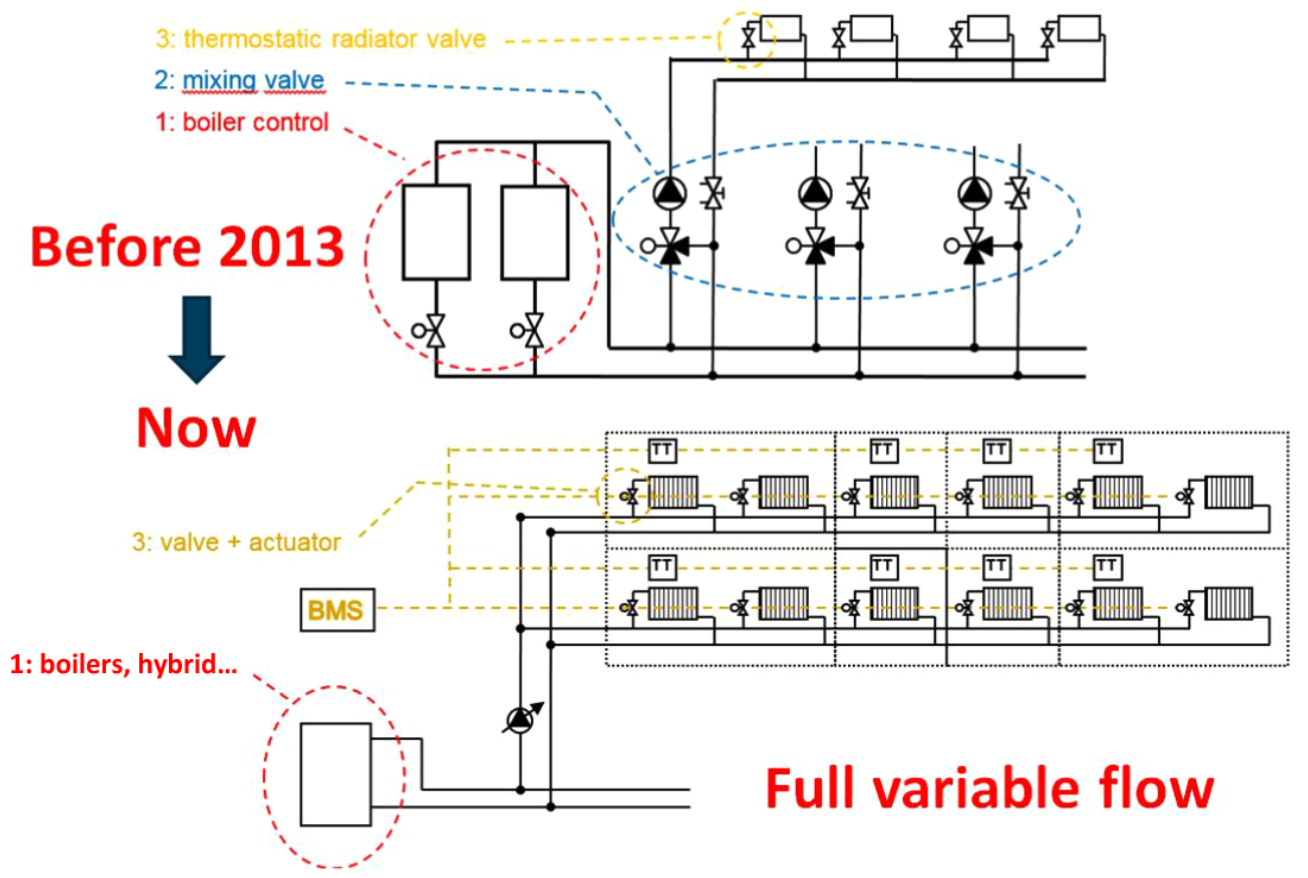

Fig. 19. - From constant flow rate to full variable flow.

characteristics for each control options. Until recently, controlling the water temperature with a constant flow where preferred because of the dynamic behaviour.

This highly simplified diagram shows only the operating principle, but it is important to know that the complexity systematically increased over the years, which led to malfunctioning systems. It was the trigger to start a research in which traditional concepts were compared with the innovative "full variable flow". Simulation and a Pareto Analysis $\left(^{5}\right)$ clearly demonstrated that this control concept scored best in terms of the key performance indicators: energy, comfort and investment.

Note that the fully variable flow pipe network of fig. 19 is greatly simplified compared to the old concept. Nevertheless, each room can easily be controlled separately, which is essential for well-insulated buildings. It is also important to know that the hydronic design contains hidden difficulties that can be perfectly solved by the Hysopt software.

41.2. Saving potential. The saving potential of a system that has been optimised in terms of hydraulic configuration and its control strategy is huge. The hydronic design and simulation software provided by Hysopt results in an annual energy saving up to $40 \%$ in its projects, with a payback period between 1 and 5 years (see fig. 20). Very often,

$\left({ }^{5}\right)$ Pareto analysis is used in decision-making since different parameters have a mutual effect, e.g. energy and comfort. 


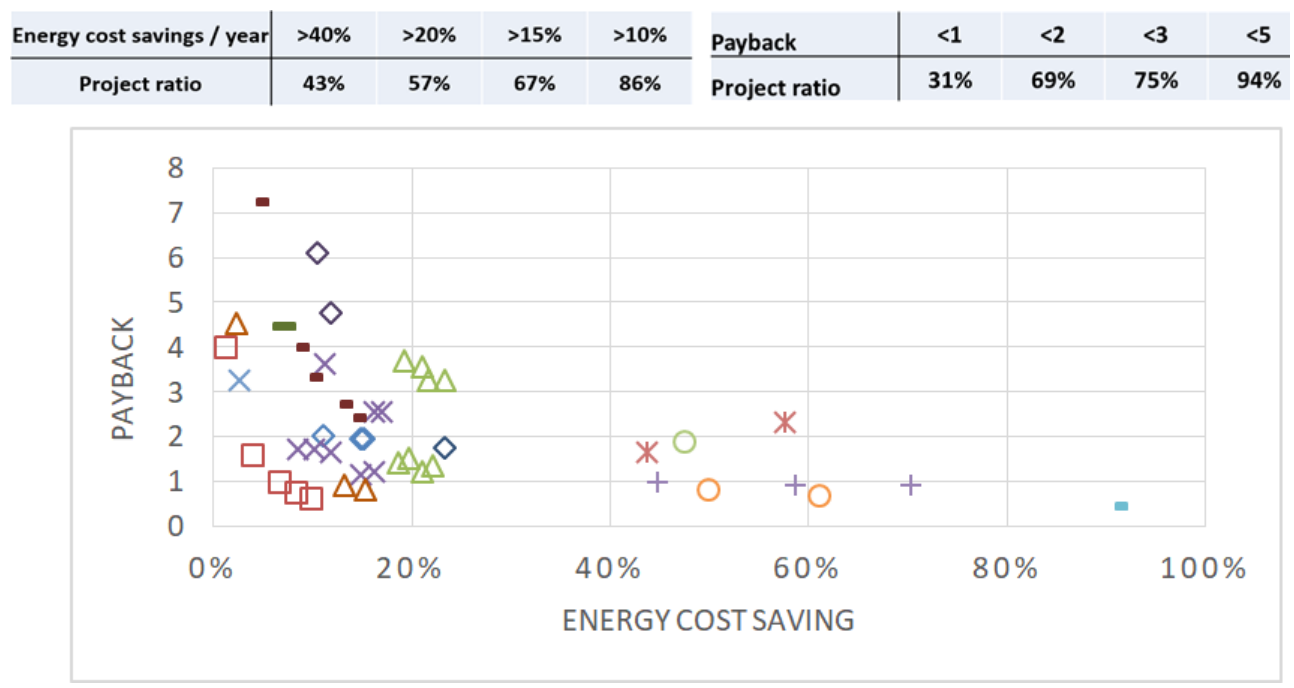

Fig. 20. - Savings vs. pay back from projects optimised with Hysopt software.

minimal adjustments in the hydraulic system configuration and the control strategy provide savings up to $20 \%$ without requiring capital expense.

4 1.3. Model based engineering. The basic operations in Hysopt are very accessible thanks to the graphical interface (impression in fig. 21). The "Base Circuit" design

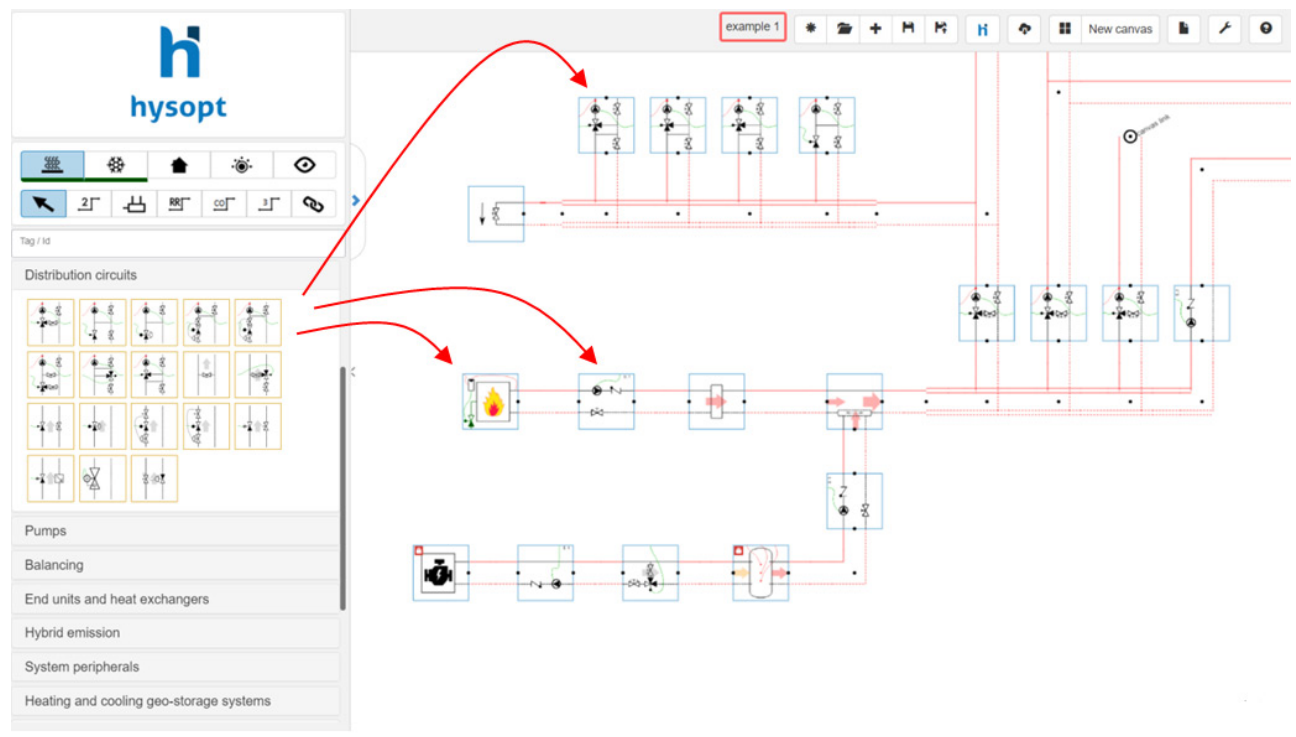

Fig. 21. - Impression from the Hysopt software. 


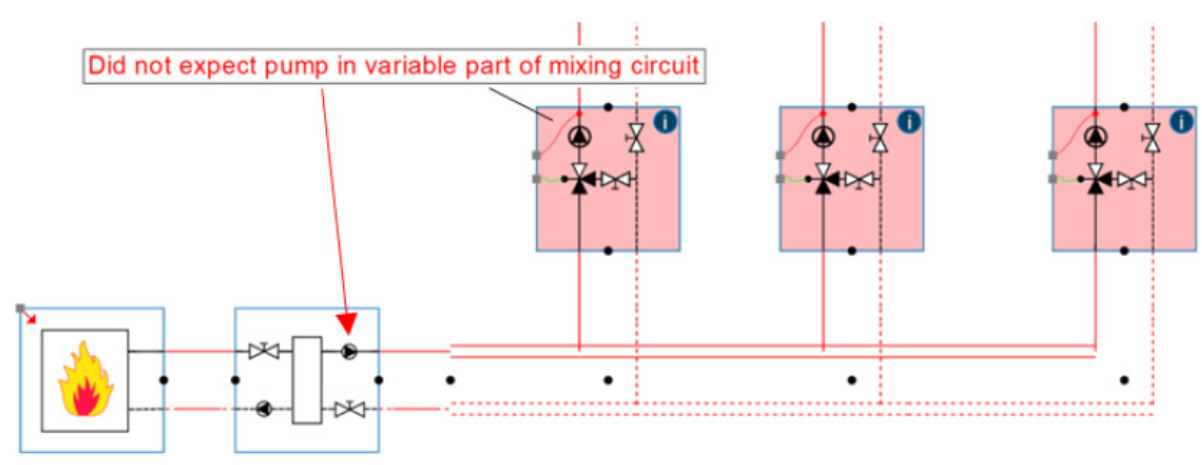

Fig. 22. - Design faults are signalled automatically and a textual instruction is provided.

method connects pre-programmed hydronic circuits to create a functional representation. Drawing a connecting line between base circuits means that pressure, temperature and flow rate are coupled. Despite this graphical interface, Hysopt is much more about system engineering calculations based on physical laws and mathematical optimization algorithms. Based on this mathematical model, all engineering calculations are optimised. Moreover, the system performance is simulated and represented in economic and ecological savings. The Hysopt software provides digital twins of each process and instrumentation diagram and can easily be shared with all stakeholders to share experiences and improve performance.

Hysopt software improves the quality of designs with unprecedented transparency and also speeds up the engineering design process. Figure 22 illustrates that design errors are highlighted, so that they can be removed at an early stage, which leads to big cost-savings and comfort assurance.

After setting the design parameters such as the power and temperature regimes, the design flows are calculated and the most suitable pipes are selected. Where until now the selection of system components such as pumps and valves has been done with rules of thumb, it is now possible to do the selection using advanced iterative optimization algorithms. This improves the controllability of the system (speed, stability, accuracy) and reduces the energy consumption of pumps. The partial load calculator can be used to analyse the flow rates and temperatures for different valve positions vs. their design values.

It is possible to design on a floor plan or on a $\operatorname{P} \& \operatorname{ID}\left({ }^{6}\right)$. Floor plans are scanned to calculate the pipe lengths. P\&IDs are recommended for complex hydraulic parts of the installation, such as the boiler room. To maintain a visual overview, different parts of the system can be viewed separately, but they are hydraulically coupled to each other at all times.

$\left({ }^{6}\right)$ A piping and instrumentation diagram (P\&ID) is a graphic representation of a system, e.g. in the process industry, that includes piping, vessels, control valves, instrumentation and other components and equipment. 

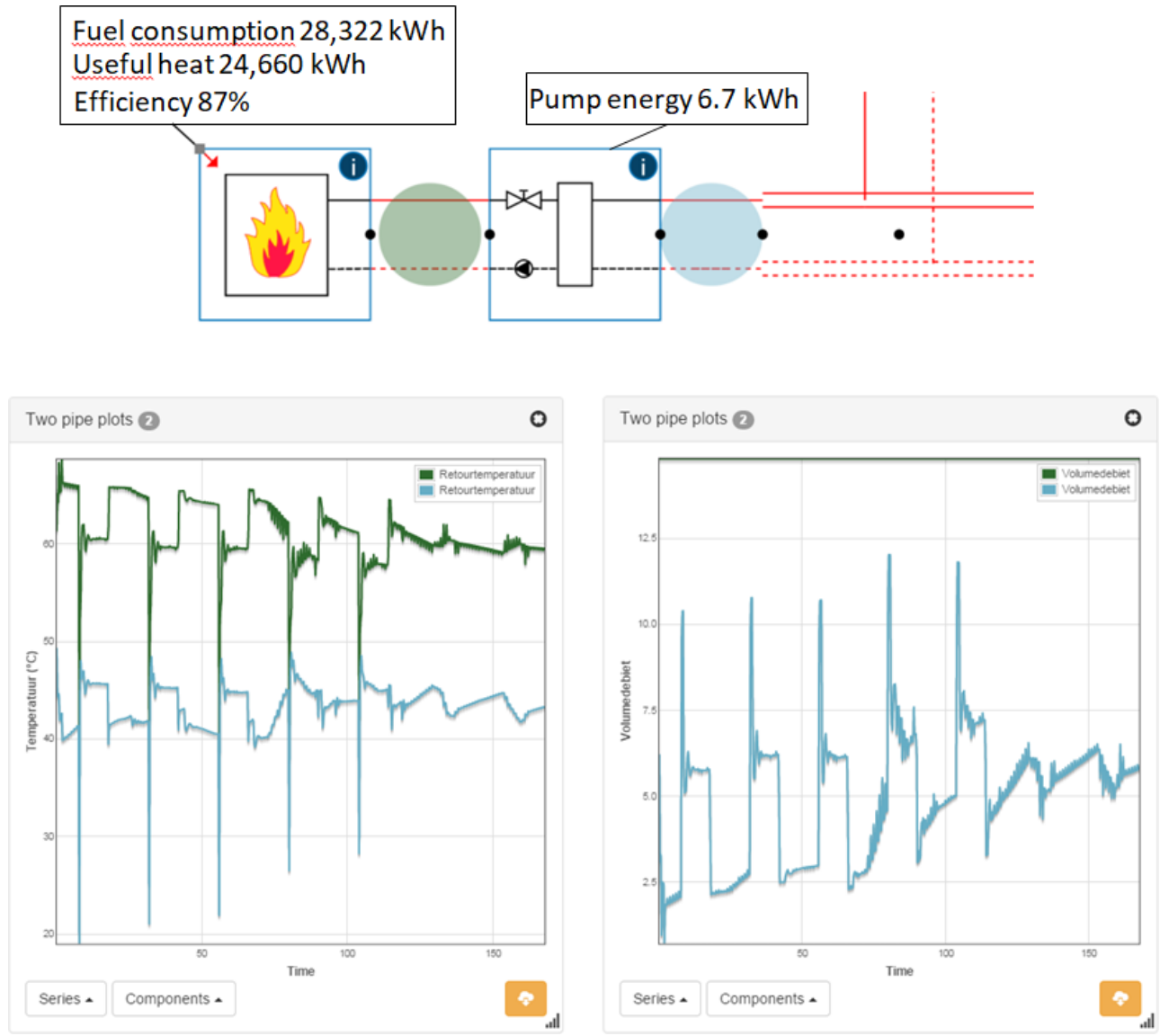

Fig. 23. - Simulation of the return temperature (left) and the flow rate (right) before and after the low loss header.

41.4. Partial Load Analysis. Hysopt's simulation capability predicts the system performance, taking into account a static partial load. The dynamic partial load behaviour can be investigated by linking the system to a building model that is exposed to set point profiles and variable weather data. The most advanced control strategies can then be implemented, using a limited number of generic control blocks. After the dynamic simulation, all system variables (flow, pressure, temperature, valve position, control signals, etc.) at all possible places in the installation can be visualized. The energy consumption of the heating and cooling units and the auxiliary energy for pumps and fans can also be evaluated.

Figure 23 shows an example of a dynamic system simulation in which the return temperature and the flow in a January week are visualized before and after the low loss header. Although the temperature in the return collector remains below $45^{\circ} \mathrm{C}$, return water is mixed with water from the supply pipe via the low-loss header, resulting in 

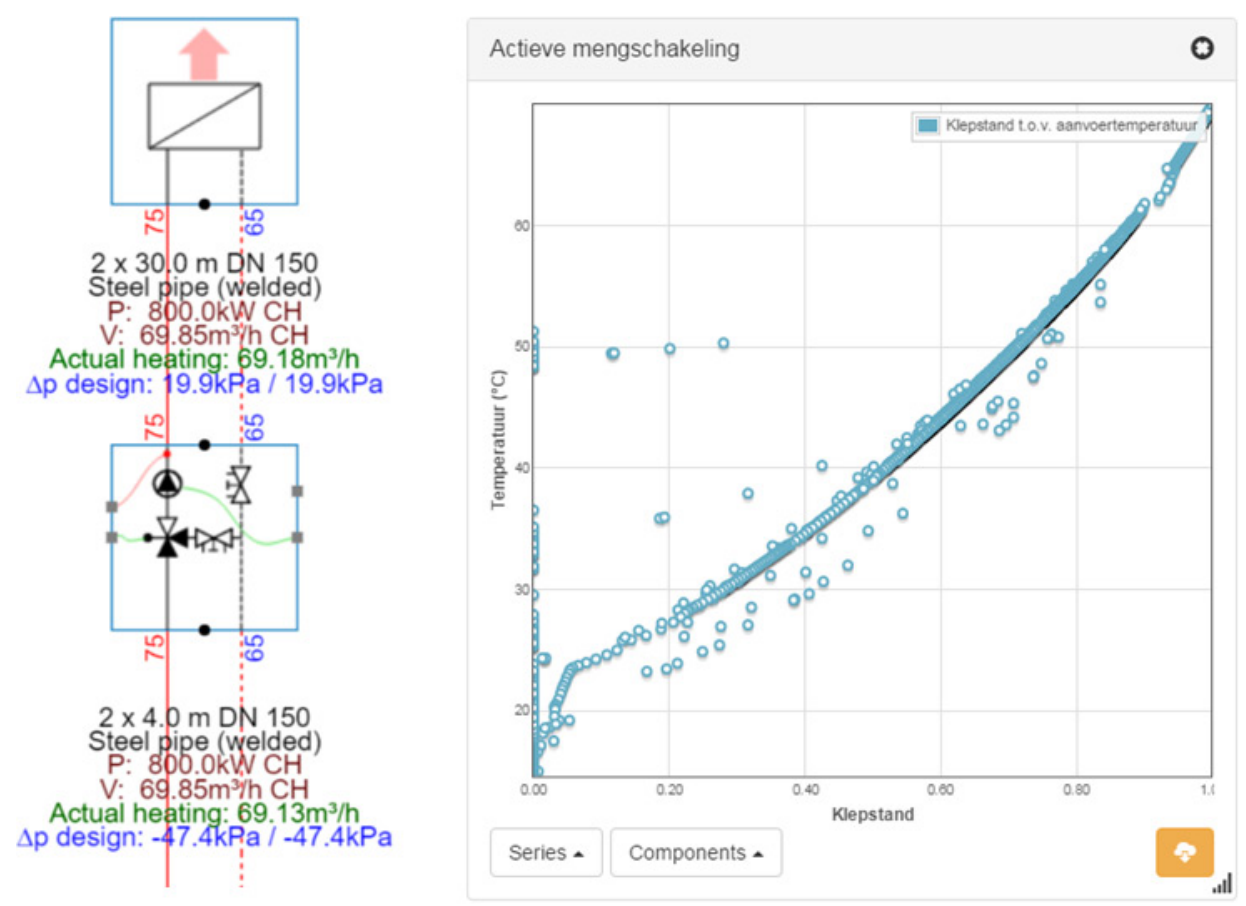

Fig. 24. - The scatter plot on the right shows the behaviour of the riser temperature according to the position of the three-way valve (power control by variable water temperature, P\&ID on the left).

a temperature rise up to $80^{\circ} \mathrm{C}$. This results in a boiler efficiency fall by approximately $10 \%$ from 97 to $87 \%$.

Figure 24 illustrates a "scatter plot" in which the relationship between two system variables can be investigated, in this case the riser temperature after the mixing circuit according to the valve position of the three-way valve. Although a relatively smooth relationship between the two variables can be observed, there are outliers that clearly deviate from the average behaviour. This can be explained by the hydraulic interactivity, whereby control valves interfere with each other. It exposes the three-way valve to pressure variations. However, the situation is not problematic thanks to the optimum component selection.

41.5. Design to perform. Hysopt provides Software as a Service, whereby the user has access to the software via a web browser. Designers always use the latest version of the software and get support when they need help. The various parties involved (engineering consultant, installer, ESCO's $\left({ }^{7}\right)$, building facility manager, etc.) collaborate

$\left({ }^{7}\right)$ An energy service company (ESCO) is a business that provides energy solutions including designs and implementation of energy savings projects. 
on the shared design platform so that they can communicate more efficiently to ensure the overall quality and performance of the scheme.

Commissioning can be done in the software using generic components or brand specific manufacturer components. It also improves the visibility of branded products and their specific benefits.

The actual performance gap between the design and its actual performance is being closed by offering full transparency. Whilst clients pursue maximum comfort at most affordable cost, and either economic or ecological goals or obligations, they can rely on Hysopt's design and simulation software to provide transparency on the actual performance of their systems and simulate the impact of their designs.

\subsection{Short introduction to Pinch for industrial application.}

4 2.1. Opportunities and restrictions. Pinch analysis, also known as pinch technology, process-, heat- or energy integration, is a methodology for minimising energy consumption of processes at industrial sites by calculating thermodynamically feasible energy targets, to be achieved by optimising heat recovery, energy supply methods and process operating conditions. The saturated temperature can be influenced, for example, by changing the pressure with the aid of compressors. The latter is actually heat pump operation.

Heat recovery is not much more than a heat exchanger that is operated under the optimum conditions (e.g. heat flow is only possible from high to low temperature, the pressure drop must not be too large, the smaller the temperature difference between the hot and the cold streams, the more efficient and expensive the heat exchanger must be etc.). When a process contains multiple heat flows at different temperatures, optimization becomes more complex.

Using the heat that is available at the highest temperature for a heat load at a very low temperature is of course not optimal. The large temperature difference results indeed in an inexpensive heat exchanger, but the ability to recover heat is not fully realized. The available heat at a lower temperature can no longer be used for a heat load at a higher temperature.

In order to optimize the potential for heat recovery, pinch analysis was developed a few decades ago. It was massively used in the chemical industry in the eighties because their energy-intensive and, moreover, continuous processes lend themselves well to it. Pinch optimization is much more complex in non-continuous processes since it requires heat and cold storage and less savings can be made.

\section{$4 \cdot 2.2$. Pinch-analysis in continuous processes.}

Step 1: collecting pinch data. Starting from an existing process (e.g., fig. 25) of which we want to optimize the energy consumption, we distinguish the basic processes (the reactors $\mathrm{R} 1$ \& $\mathrm{R} 2$ and the separator $\mathrm{C} 1$ ) vs. the utilities (heating $\mathrm{H}$, e.g. steam and cooling $\mathrm{C}$, e.g. cooling water). Next, the mass and energy balance of the basic processes is drawn up as shown in fig. 26.

A basic process is for example the cooking of potatoes, and not the generation of steam required for cooking. The existing heat recovery (two processes to process heat 


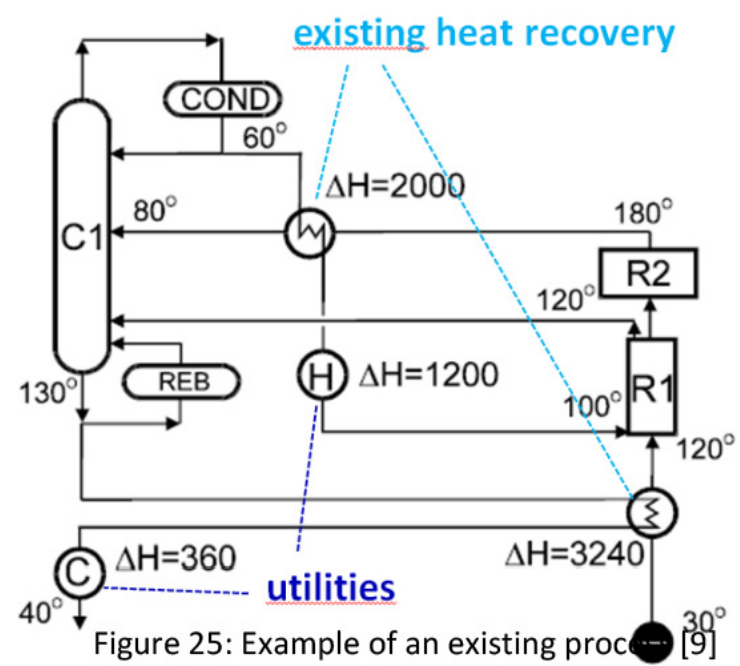

Fig. 25. - Example of an existing process [10].

exchangers) is not taken into account as these may not be optimally positioned.

Hot streams are process flows that need cooling, cold streams need heating. In the case of sensible heat, so no phase change occurs, we calculate the "heat capacity flow rate" CP for all basic processes as the exchanged heat divided by $\Delta T$. Logically, heat is extracted when the temperature drops.

Energy saving and efficiency _ 2020

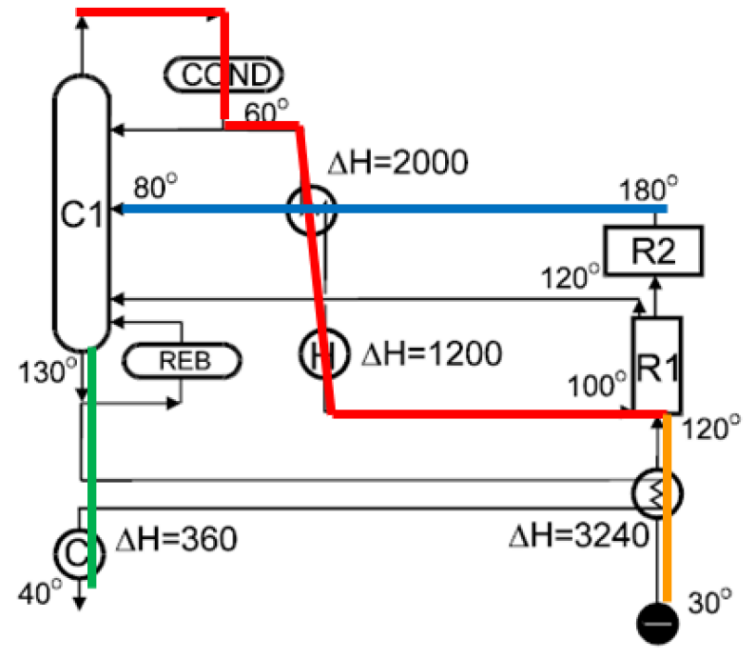

\begin{tabular}{ll} 
Red process flow & \\
\hline Start temperature & $60^{\circ} \mathrm{C}$ \\
End temperature & $100^{\circ} \mathrm{C}$ \\
Delta T & $40^{\circ} \mathrm{C}$ \\
Supplied energy & $3200 \mathrm{E} . \mathrm{U}$. \\
CP & $80 \mathrm{E} . \mathrm{U} /{ }^{\circ} \mathrm{C}$ \\
Blue process flow & \\
\hline Delta T & $-100^{\circ} \mathrm{C}$ \\
Supplied energy & $-2000 \mathrm{E} . \mathrm{U}$. \\
Cp & $20 \mathrm{E} . \mathrm{U} /{ }^{\circ} \mathrm{C}$ \\
Green process flow & \\
\hline Delta T & $-90^{\circ} \mathrm{C}$ \\
Supplied energy & $-3600 \mathrm{E} . \mathrm{U}$. \\
Cp & $40 \mathrm{E} . \mathrm{U} /{ }^{\circ} \mathrm{C}$ \\
Yellow process flow & \\
\hline Delta T & $90^{\circ} \mathrm{C}$ \\
Supplied energy & $3240 \mathrm{E} . U$. \\
Cp & $36 \mathrm{E} . \mathrm{U} /{ }^{\circ} \mathrm{C}$
\end{tabular}

Fig. 26. - Flow-sheet of basic processes, indicating the mass and energy balance [10]. 

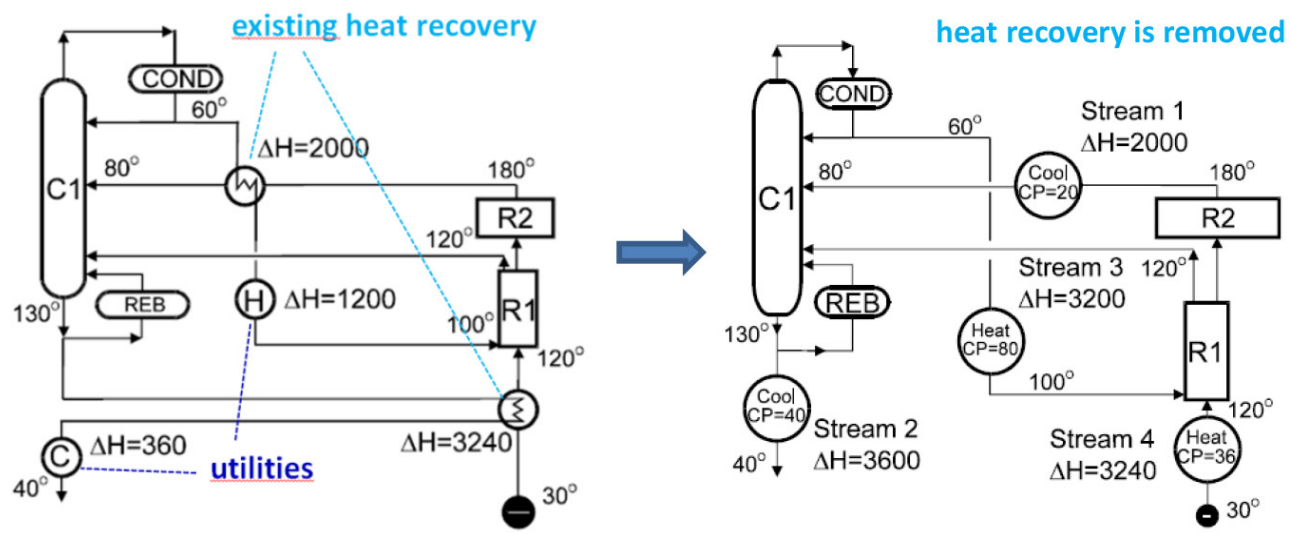

Fig. 27. - Translation form the Process Flow-sheet (left) into the Data Extraction Flow-sheet (right) [10].

\begin{tabular}{l|c|c|c|c|c|}
\cline { 2 - 6 } & $\begin{array}{c}\text { Stream } \\
\text { No }\end{array}$ & $\begin{array}{c}\text { Stream } \\
\text { Type }\end{array}$ & $\begin{array}{c}\text { Start } \\
\text { Temperature }(\mathrm{Ts}) \\
\left({ }^{\circ} \mathrm{C}\right)\end{array}$ & $\begin{array}{c}\text { Target } \\
\text { Temperature }(\mathrm{Tt}) \\
\left({ }^{\circ} \mathrm{C}\right)\end{array}$ & $\begin{array}{c}\text { Heat Capaity } \\
\text { Flowrate } \\
(\mathrm{kW} / \mathrm{C} \mathrm{C})\end{array}$ \\
\hline $\begin{array}{l}\text { Hot: } \\
\text { has te be cooled }\end{array}$ & 1 & Hot & 180 & 80 & 20 \\
\cline { 2 - 7 } & 2 & Hot & 130 & 40 & 40 \\
\hline $\begin{array}{l}\text { Cold: } \\
\text { has te be heated }\end{array}$ & 3 & Cold & 60 & 100 & 80 \\
\cline { 2 - 7 } & 4 & Cold & 30 & 120 & 36 \\
\hline
\end{tabular}

$\mathrm{CP}$ : capacity factor $[\mathrm{kW} / \mathrm{K}]$

Utilities: Steam at $200^{\circ} \mathrm{C} . \mathrm{CW}$ at $25^{\circ} \mathrm{C} \Rightarrow 30^{\circ} \mathrm{C}$

Fig. 28. - Data Extraction Table [10].

After the "flow-sheet" of this process has been translated into "Pinch data", the "data extraction flow sheet" of fig. 27 can be prepared. Energy units (EU) may be kWh, kW etc.

The data required later in the analysis can now be presented schematically in the table of fig. 28 .

Step 2: drawing up the pinch curves and detecting the energy targets. Now the "composite curves" of fig. 29 with the energy targets can be set up. These are temperatureenthalpy curves of heat load and heat supply in the process. In the example, two heat flows need cooling: $100{ }^{\circ} \mathrm{C} \times 20 \mathrm{~kW} /{ }^{\circ} \mathrm{C}=2000 \mathrm{~kW}$ and $90^{\circ} \mathrm{C} \times 40 \mathrm{~kW} /{ }^{\circ} \mathrm{C}=3600 \mathrm{~kW}$, together $5600 \mathrm{~kW}$.

These heat flows are now arranged according to temperature:

- Between $180^{\circ} \mathrm{C}$ and $130^{\circ} \mathrm{C}$ there is only one heat flow, so that the specific heat at constant pressure $\mathrm{Cp}$ of the combination is equal to $\mathrm{Cp}$ of that one heat flow: $20 \mathrm{~kW} /{ }^{\circ} \mathrm{C}$. 

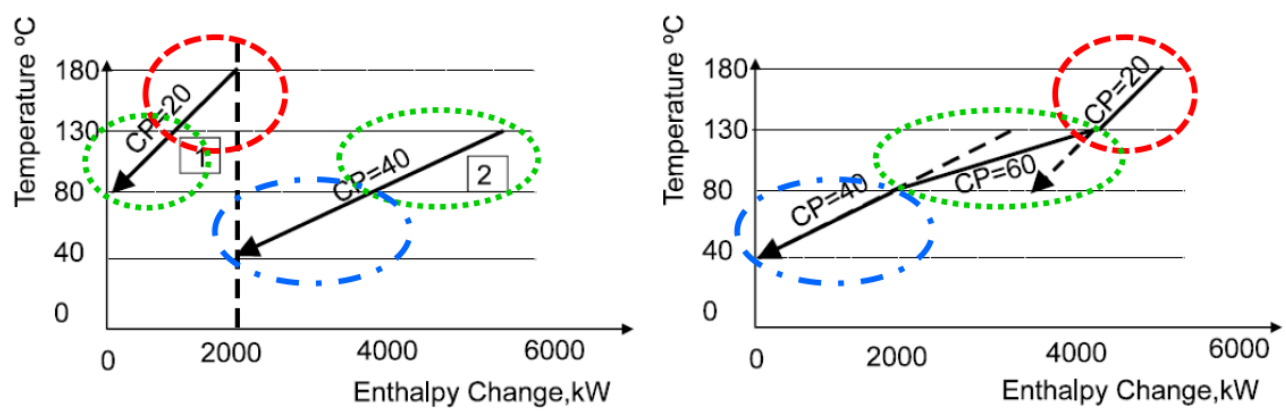

Fig. 29. - Composite curve (load curve only) [10].
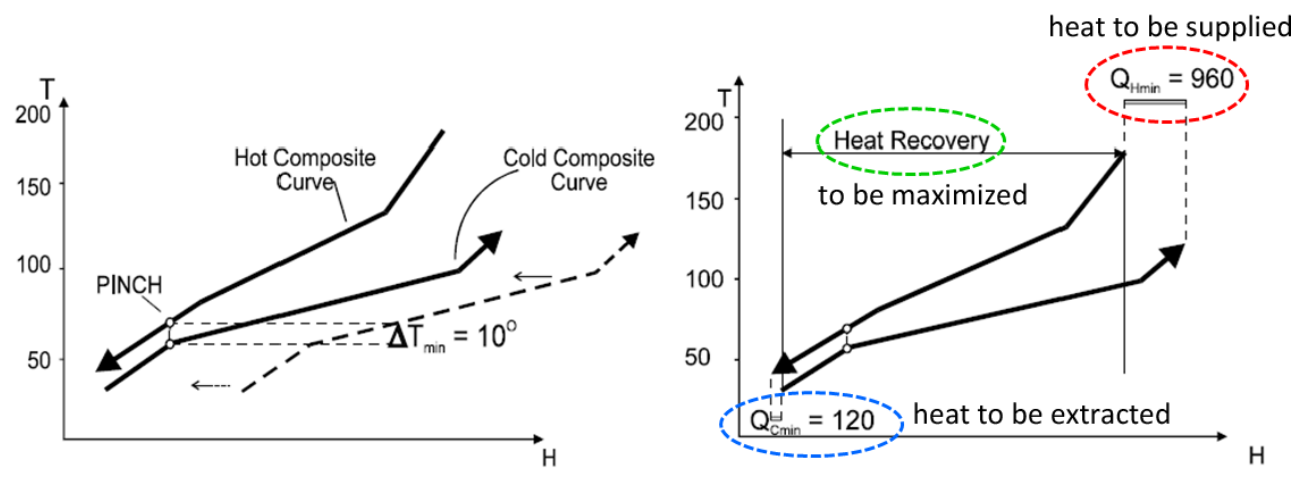

Fig. 30. - Composite curves and energy targets [10].

- From $130^{\circ} \mathrm{C}$ to $80^{\circ} \mathrm{C}$ there are two heat flows, so that $\mathrm{Cp}$ of the combination is equal to the sum of both $\mathrm{Cp}$ values, or $20+40=60 \mathrm{~kW} /{ }^{\circ} \mathrm{C}$.

- Between $80^{\circ} \mathrm{C}$ and $40^{\circ} \mathrm{C}$ there is only one heat flow, so that $\mathrm{Cp}$ of the combination is $40 \mathrm{~kW} /{ }^{\circ} \mathrm{C}$.

The demand and load curve must be drawn up in a similar way. Both curves of fig. 30 show the image of a counter flow heat exchanger, not as a result of one heating and one cooling process, but with different heat flows that fit together.

This "composite curves" can be used to determine the energy targets just by shifting one of the two curves horizontally. The heat is consequently transferred to other parts of the process. The smallest temperature difference (vertical) between the two curves is called the "pinch point" or simply "pinch".

By shifting the lower curve more to the right, all temperature differences (including the pinch) get larger, making it possible to select smaller, less expensive heat exchangers. On the other hand, this reduces the amount of heat that can be recovered, resulting in increasing energy consumption. As a result, more heat must be supplied and removed, represented, respectively, by the red and blue dashed lines in fig. 30 . 

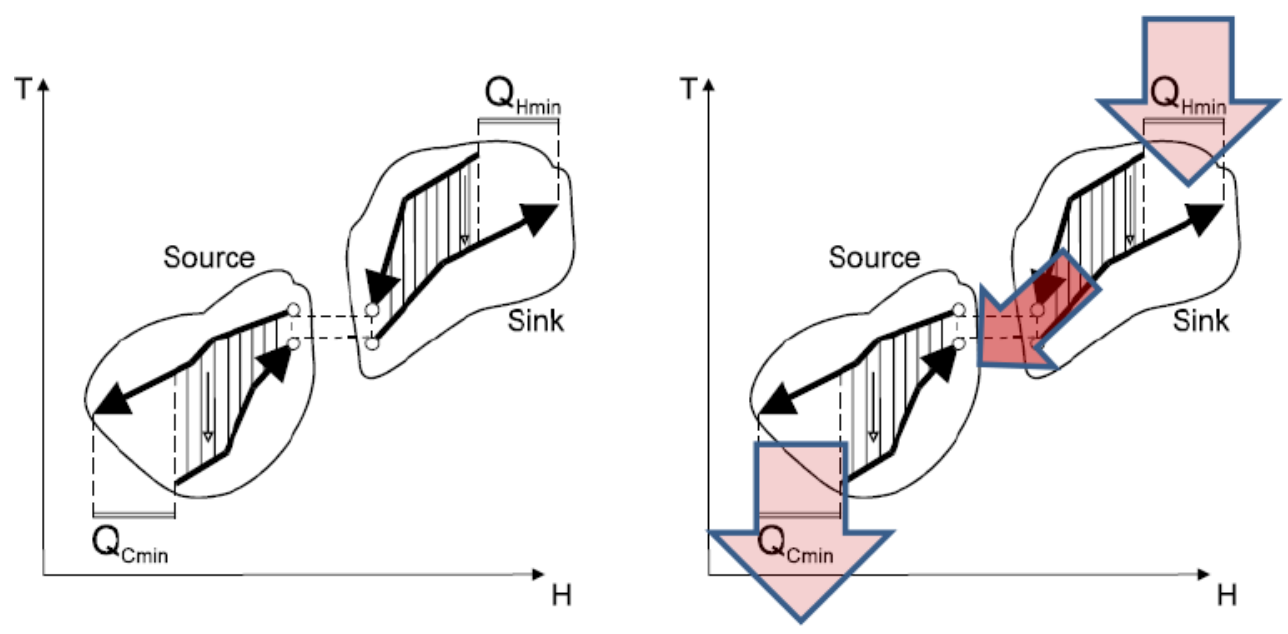

Fig. 31. - Suboptimal heat recovery to be avoided [10].

The minimum heating need is 960 units, which is smaller than the 1200 units of the original concept. The potential energy saving is therefore $1200-960=240$ units. Yet there was already energy recovery and the same pinch was chosen here. This energy saving is the result of a further fragmentation of heat load and heat supply.

By separating the part of the process above the pinch from the part below the pinch as in fig. 31, it becomes clear which heat exchange increases energy consumption and should therefore be avoided. The system under the pinch needs cooling and is therefore a heat source. When heat is added, either from a utility or heat recovery within the system, more heat must be removed by cooling water, active cooling, etc. The system above the pinch needs heating and is therefore a heat sink. When heat is dissipated from this (either to a utility or via heat recovery within the system), more heat must be supplied from the utility (steam, ...). Heat transfer from the top to the bottom of the pinch is a combination of the two previous cases and, as a result, this must also be avoided.

Step 3: Optimization of the utilities - construction of the "grand composite curve". The energy for heating and cooling often comes from multiple sources: steam at different pressures, cooling water (cold water at a higher temperature, obtained by passive cooling, e.g. cooling towers) or chilled water (cold water at a lower temperature, obtained by active cooling, e.g. chillers) ... In order to get savings on the most expensive sources (high pressure steam, chilled water), these can be partly replaced by the cheaper sources (low pressure steam, cooling water).

In fig. 32, part of the high pressure (HP) steam has been replaced by low pressure (LP) steam, so that the energy supplied by the low pressure steam does not have to be supplied by the high pressure steam. This can be visualized by moving the top line to the right. The possibilities for this depend on the temperature levels, because heat can only flow 

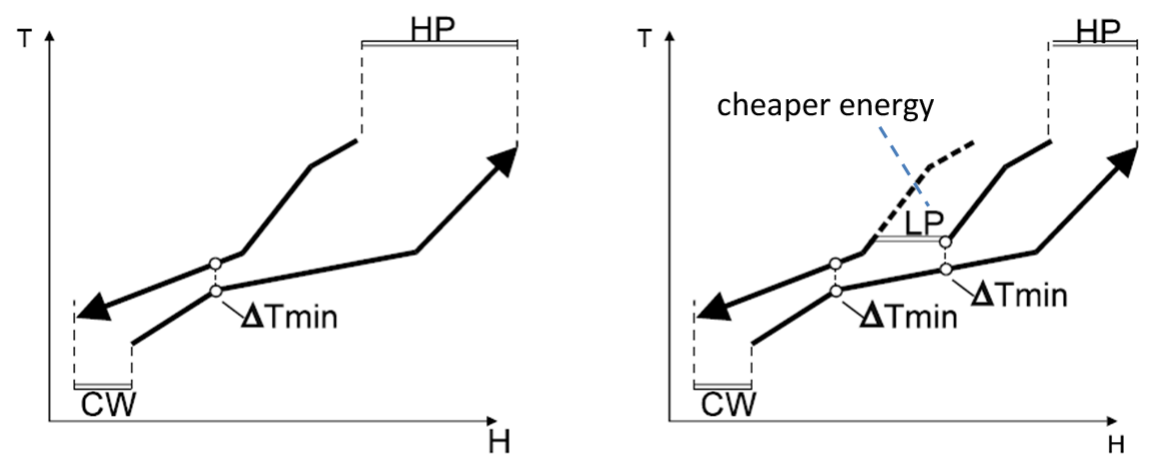

Fig. 32. - Saving expensive sources by moving to cheaper sources. CW can be cooling water or chilled water, depending on the temperature [10].

spontaneously from high to low temperature. The vertical position of the low pressure line depends on the steam pressure and the corresponding saturation temperature. The limit to which point can be shifted also depends on the proposed pinch.

The shape of the "composite curves" changes with every addition of a new utility, which makes the analysis more complex. That is why the "grand composite curve" is introduced. Its construction starts with the "composite curve", shown in (a) of fig. 33. First, each curve is shifted vertical with half a pinch until they touch each other (b). This ensures that after optimization, a temperature difference remains to exchange heat between the process flows and the utilities.

The "grand composite curve" of fig. 33 can now be constructed by plotting the heat

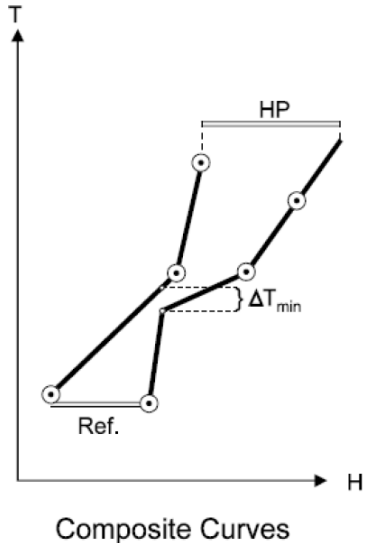

(a)

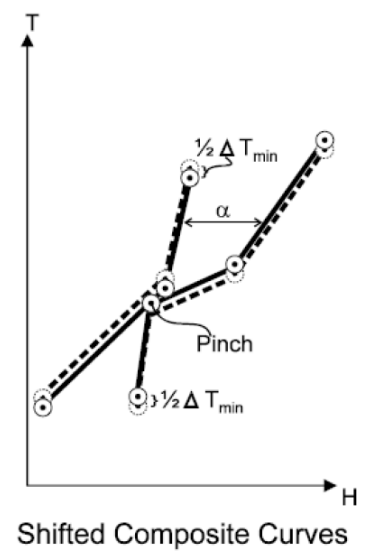

(b)

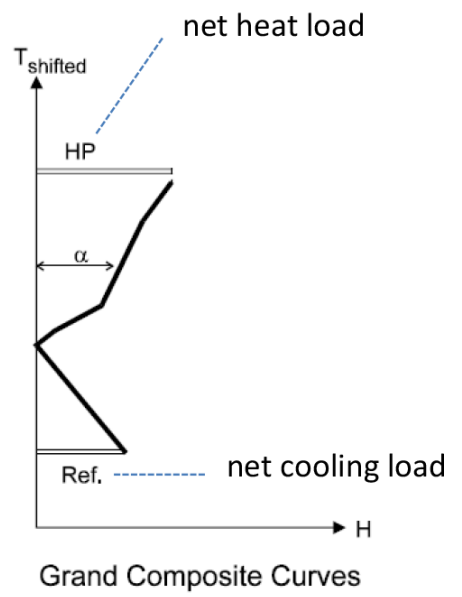

(c)

Fig. 33. - Construction of the grand composite curve [10]. 


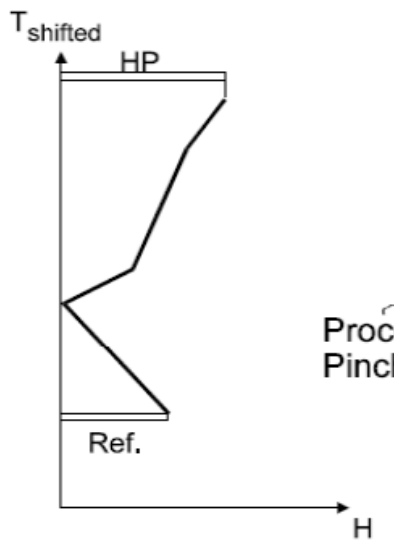

(a)

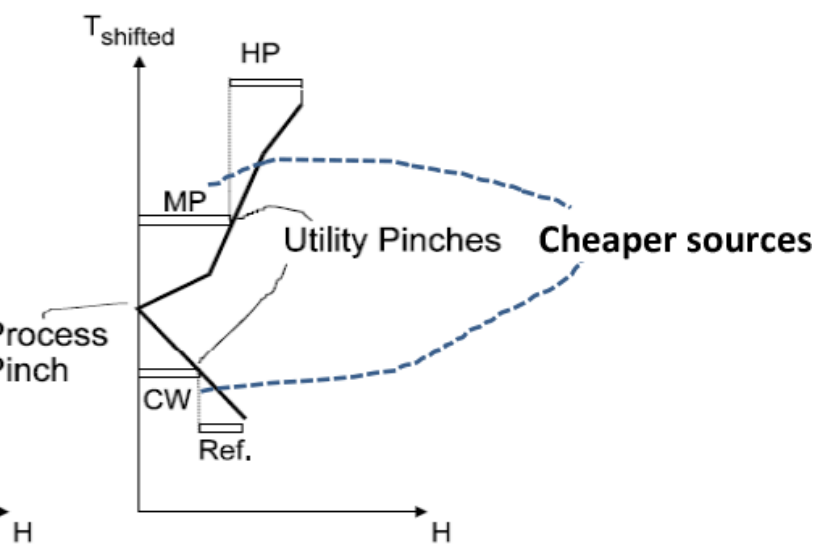

(b)

Fig. 34. - Grand composite curve in the search for cheaper sources [10].

flows (enthalpy differences) as a function of the temperature (c). The energy needs are identical, only more clearly presented for further analysis.

In (a) of fig. 34 high pressure steam is used for heating while ice water is used for cooling. Introduction of the cheaper medium pressure steam (MP) in (b) assumes a horizontal line on the saturation temperature of this steam, until it touches the "grand composite curve". The remaining heat by high pressure steam (HP) can now be easily calculated. A similar optimization can be implemented below the pinch, replacing chilled water by the cheaper cooling water.

Pinch analysis can also be used to determine how installations can be optimized by using $\mathrm{CHP}\left({ }^{8}\right)$ and heat pumps.

\section{5. - Conclusion}

This paper presented a vision on how to deal with energy efficiency of products and systems. After an introduction in which the boundary conditions were described and in which various processes were schematized, the energy labels of products were discussed. It was clarified that system designs such as climate control systems and heat recovery in industrial processes require a different approach. Therefore, the design of climate control systems with Hysopt was discussed, and with respect to industrial processes, pinch technology was explained. It was concluded that for systems with a higher complexity and scale, the use of design software has become essential.

$\left(^{8}\right)$ Combined production of heat and power (CHP), see footnote $\left({ }^{4}\right)$. 


\section{REFERENCES}

[1] Van Riet Freek, Vandenbulcke Roel, Cleiren Jonas and Verhaert Ivan, "Hydronic Optimization of Hybrid Heat Production Systems: a Methodology Based on Base Circuits", to be published in the Proceedings of Building Simulation 2019: 16th Conference of IBPSA (2019).

[2] VAn Riet Freek, Hydronic design of hybrid thermal production systems in buildings, $\mathrm{PhD}$ Thesis (University of Antwerp) 2019.

[3] Vandebulcke Roel, Hydronic Simulation and Optimisation: a simulation based study on the energy efficiency and controllability of hydronic heating systems, $\mathrm{PhD}$ Thesis (University of Antwerp) 2013.

[4] Vandenbulcke Roel, Mertens Luc and Janssen Eddy, "A simulation methodology for heat and cold distribution in thermo-hydronic networks", Build. Simul., 5 (2012) 203 (Best Paper Award of Building Simulation).

[5] VAn Riet Freek and Verhaert IVAn, "Hydronic configurations of hybrid heat production systems in buildings: General design methodology and case studies", Appl. Therm. Eng., 164 (2019) 114454.

[6] Van Riet Freek, Janssen Eddy, Steenackers Gunther and Verhaert Ivan, "Hydronic design of cogeneration in collective residential heating systems: state-of-theart, comparison and improvements", Appl. Therm. Eng., 148 (2019) 1246.

[7] Energy circle: Janssen EdDy, Energy Systems (University of Antwerp) 2019 (in Dutch).

[8] Trias Energetica: https://www.eurima.org/energy-efficiency-in-buildings/triasenergetica (consulted on December 2019).

[9] Ecodesign: https://ec.europa.eu/growth/industry/sustainability/ecodesign_en (consulted on December 2019).

[10] Introduction to Pinch Technology, https://www.ou.edu/class/che-design/a-design/ Introduction\%20to\%20Pinch\%20Technology-LinhoffMarch.pdf (consulted on December 2019). 